\title{
Spinal Endoscopy and Lysis of Epidural Adhesions in the Management of Chronic Low Back Pain
}

\author{
Laxmaiah Manchikanti, MD*, Bhupinder Saini, MD**, and Vijay Singh, MD\#
}

Spinal endoscopy with epidural adhesiolysis is an interventional pain management technique which emerged during the 1990s. It is an invasive but important treatment modality in managing chronic low back pain that is nonresponsive to other modalities of treatment, including percutaneous spring guided adhesiolysis and transforaminal epidural injections. While epidural adhesions most commonly result following surgical intervention of the spine, leakage of disc material into the epidural space following an anular tear, or an inflammatory response can also result in their formation. Even though advanced technology, including computerized tomography and magnetic resonance imaging, have made significant advances in the diagnosis of epidural fibrosis, it is believed that epidural adhesions resulting in chronic persistent pain are poorly managed.

Percutaneous endoscopic lysis of epidural scar tissue has been shown to be cost effective and a safe modality. This review discusses various aspects of endoscopic adhesiolysis, including clinical effectiveness, complications, rationale, and indications.

Keywords: Epidural fibrosis, endoscopic lysis of epidural adhesions, chronic low back pain, spinal endoscopy
Interventional techniques in the management of low back pain, including spinal endoscopy and epidural adhesiolysis, continue to be some of the most contentious modalities, along with surgical interventions and other modalities (1-6). Among all the chronic painful conditions, low back pain is the most common, burdening approximately $15 \%$ to $39 \%$ of the population with serious financial and social consequences (7-18). Apparently, low back pain ranks first among musculoskeletal disorders (7). Even though it is widely believed that most episodes of low back pain are short-lived and that $90 \%$ of patients recover in about 6 weeks $(12)$, multiple studies $(10,11,15,16)$ have shown evidence to the contrary. It has been shown that as many as $79 \%$ of patients continue to suffer with chronic or recurrent low back pain at 12 months.

While disorders of the disc and joints play a major role in causation of low back pain, failed low back surgery syn-

From Pain Management Center of Paducah, Paducah, Kentucky; Advanced Pain Management, Milwaukee, Wisconsin; and Pain Diagnostic Associates, Niagara, Wisconsin. *Dr. Manchikanti is Medical Director of Pain Management Center of Paducah, **Dr. Saini is Medical Director of Advanced Pain Management, and "Dr. Singh is Medical Director of Pain Diagnostic Associates. Address correspondence: Laxmaiah Manchikanti, MD, 2831 Lone Oak Road, Paducah, Kentucky 42003. E-mail: drm@asipp.org drome, also known as failed management syndrome or postlumbar laminectomy syndrome, is a growing entity in modern medicine, with an estimated $5 \%$ to $40 \%$ of lumbar surgeries resulting in failed back surgery syndrome; staggering statistics show failure rates reaching as high as $68 \%$ (3-6, 19-103). Though these often result from surgery that was inadequate, incorrect, or unnecessary, this syndrome also results following a well-indicated and well-performed surgical intervention.

Endoscopic adhesiolysis is based on the premise that the epidural space can be accessed safely by using flexible fiberoptic catheters entering via the sacral hiatus. It facilitates three-dimensional visualization of the contents of the epidural space and provides the operator with the ability to steer the catheter toward structures of interest. This procedure allows examination of a specific nerve root and its pathology and treatment by injection of a drug directly in the root, along with the ability to expand the epidural space with normal saline.

\section{HISTORICAL CONSIDERATIONS}

Epidural injection for chronic low back pain was performed by Pasquier and Leri in 1901 (104). Eight years later, reports on cures of sciatica with epidural anesthesia were made by Caussade and Queste (105). The initial epidurography was performed in 1921 by Sicard and Forestier (106). Cyriax (107) reported his extensive experi- 
Table 1. Historical evolution of spinal endoscopy

\begin{tabular}{|c|c|c|c|}
\hline$\diamond$ & 1931 Burman & - & Direct visualization of spinal canal \\
\hline$\diamond$ & 1936 Stern & - & Described a spinascope for in vivo examination of spinal canal \\
\hline$\diamond$ & 1937 Pool & - & First examination with myeloscope \\
\hline$\diamond$ & 1942 Pool & - & Used diagnostically in preparation for surgery \\
\hline$\diamond$ & 1967 to 1997 Ooi et al & - & $\begin{array}{l}\text { Developed endoscope in } 1960 \mathrm{~s} \\
\text { Miniaturized with advent of fiberoptic light source in } 1970 \mathrm{~s}\end{array}$ \\
\hline$\diamond$ & 1981 Ooi et al & - & Published changes in the cauda equina during Laseque's test \\
\hline$\diamond$ & 1985 Blomberg & - & $\begin{array}{l}\text { Epidural space contents varied in regard to fat and connective } \\
\text { tissue }\end{array}$ \\
\hline$\diamond$ & 1989 Blomberg and Olson - & - & $\begin{array}{l}10 \text { epiduroscopies on patients scheduled for partial laminecto- } \\
\text { mies }\end{array}$ \\
\hline$\diamond$ & 1990s Heavner et al & - & $\begin{array}{l}\text { Endoscopic evaluation of epidural and subarachnoid spaces in } \\
\text { animals and cadavers }\end{array}$ \\
\hline$\diamond$ & 1991 Shimoji et al & - & 0.5- to 1.4 -mm flexible fiberoptic scopes \\
\hline$\diamond$ & 1991 Saberski and Kitahata- & & Started evaluations of several fiberoptic systems \\
\hline$\diamond$ & 1996 Saberski and Kitahata- & & Review of clinical basis \\
\hline$\bullet$ & 1999 Manchikanti et al & - & Endoscopy in postlumbar laminectomy \\
\hline$\diamond$ & 2000 Manchikanti et al & - & Safety of endoscopic adhesiolysis \\
\hline$\diamond$ & 2001 Richardson et al & - & Prospective case series \\
\hline
\end{tabular}

ence with 20,000 patients who showed significant improvement with large volumes of caudal epidural anesthetic. Brown (108) also injected large volumes ranging from 40 to $100 \mathrm{~mL}$ of normal saline, followed by the injection of $80 \mathrm{mg}$ of methylprednisolone in an attempt to mechanically disrupt and prevent preformation of presumably fibrotic lesions in patients with sciatica. Over the years, various authors (109-118) have studied the effectiveness of percutaneous adhesiolysis facilitated by a spring guided catheter. Development of endoscopic adhesiolysis added an another dimension to percutaneous adhesiolysis, with three-dimensional visualization of epidural contents (119, 120).

A review of the medical literature indicates that clinicians have been working with various types of endoscopes for over 60 years, with varying degrees of success (119). Integration of fiberoptic technology with computer-enhanced imaging provided a new medium for viewing the CNS (120). The possibility of direct visualization of the spinal canal and its contents first surfaced in 1931 based on the pioneering work of Burman (121); however, until the advent of flexible fiberoptic light sources and optics (122), direct visualization of spinal contents could not be achieved. Burman (121) concluded that myeloscopy was limited by the available technology, but that with higher quality instrumentation, a better postmortem examination of the cauda equina could be performed in situ. He felt that the ability to visualize the contents of the spinal canal might be especially important in establishing a diagnosis of tumor or inflammation. Stern (123), in 1936, described a spinascope, which was specifically designed for the in vivo examination of the spinal canal contents during spinal anesthesia. Stern (123) predicted that this technology could obviate the necessity for extensive exploratory laminotomies, even though the instrument was never used clinically.

Pool (124), in 1937, attempted to improve the preoperative diagnostic assessment of lumbar-sciatic syndrome by examining an anesthetized patient. However, only a fleeting glimpse of the lumbosacral nerve roots was possible due to hemorrhage which obscured the field of vision. In subsequent evaluations, seven volunteer patients without complications were examined $(125,126)$. In these evaluations, the cauda equina and blood vessels, and blood flow through epidural vessels were first visualized and reported $(125,126)$. Pool $(125,126)$ published a summary of his experience with 400 patients with endoscopic evaluation, used to identify neuritis, herniated nucleus pulposus, hypertrophied ligamentum flavum, primary and metastatic 
neoplasms, varicose vessels, and arachnoid adhesions. Despite his successes and the relative ease of performing such examinations, no further reports of this technique appeared in the literature until 1967.

In the late 1960s and 1970s, Ooi et al (127-131) developed an endoscope for intradural and extradural examinations, which was miniaturized enough to be inserted between lumbar spinous processes. Ooi et al (132-134) performed 208 myeloscopies using various types of equipment from 1967 to 1977 , with publication of their technique of myeloscopy and cauda equina blood flow changes during Lasègue's test in 1981. Ooi et al (135), however, reported that abdominal straining, coughing and sneezing did not alter the blood flow; it only caused mild movements of the cauda equina in the lateral position.

Blomberg (136) was the next to describe a method of epiduroscopy and spinaloscopy in 1985, studying the anatomical variations of the epidural space and the appropriate delivery of epidural anesthetics. Blomberg (136) reported the wide variation of the contents of the epidural space. He reported that epidural adhesions between the dura mater and the ligamentum flavum restricted the opening of the epidural space. Blomberg and Olsson (137), in 1989, reported experience with 10 epiduroscopies of patients scheduled for partial laminectomies for herniated lumbar discs. Following the experience of endoscopy in live patients, Blomberg (138) felt that the conclusions drawn from previous autopsy work were not necessarily applicable to the clinical setting. He determined that the epidural space was indeed only a potential space that remained open for brief periods of time when fluid or air was injected. Blomberg (138) also confirmed the presence of a dorsomedian connective tissue band that divided the epidural space into compartments. Blomberg (138), in addition, determined that the midline approach to the epidural space was often associated with bleeding and that a paramedian approach was less likely to cause this complication.

In 1991, Saberski and Kitahata began evaluations of several fiberoptic systems for use in clinical epiduroscopy $(119,120)$. Heavner et al $(139,140)$ in the early 1990 s reported endoscopic evaluation of the epidural and subarachnoid spaces in rabbits, dogs and human cadavers, with the aid of a flexible endoscope. Since then multiple publications (141-150) have described various aspects of spinal endoscopy, including clinical basis, safety, and cost effectiveness. Table 1 illustrates the historical evolution of spinal endoscopy.

\section{ENDOSCOPIC ADHESIOLYSIS}

Since the introduction of epidural corticosteroids, it has always been the objective of pain specialists to deliver them close to the site of pathology, presumably onto an inflamed nerve root (1). For many reasons, this objective has been hindered in caudal as well as interlaminar delivery of epidural corticosteroids (10). Consequently, the reports of effectiveness of epidural corticosteroids have shown a wide disparity, ranging from $18 \%$ to $90 \%$ effectiveness (1).

The purpose of endoscopic epidural lysis of adhesions is to directly visualize the contents of the epidural space, lyse the adhesions and eliminate deleterious effects of scar and direct application of drug, thus assuring delivery of high concentrations of injected drugs to the target areas. Thus, spinal endoscopy with lysis of adhesions incorporates multiple therapeutic goals into one treatment, similar to percutaneous lysis of adhesions with a spring guided catheter, with added advantages of direct visualization of the epidural space and its contents, a three-dimensional view, and increased steerability of endoscopic equipment with a fiberoptic catheter.

Epidural endoscopy is gaining popularity as a minimally invasive technique for adhesiolysis and accurate placement of injectate intended for delivery in the epidural space. However, similar to the many therapeutic interventions already available for the treatment of chronic low back pain, including surgery, drugs, manipulation, physical therapy, behavioral therapy, and neural blockade, the effectiveness of spinal endoscopy has not been demonstrated conclusively (1). Nomenclature used to describe spinal endoscopy is summarized Table 2.

Table 2. Nomenclature utilized in descrip-
tion of spinal endoscopy

Pain Physician Vol. 4, No. 3, 2001 


\section{PATHOPHYSIOLOGY}

Epidural fibrosis is a progressive disease. It is an inflammatory reaction of the arachnoid, a fine nonvascular and elastic tissue enveloping the CNS (103). There are many possible etiologies of epidural fibrosis, including an anular tear, hematoma, infection, surgical trauma, or intrathecal contrast media. LaRocca and McNab (151) have demonstrated the invasion of fibrous connective tissue into the postoperative hematoma as a cause of epidural fibrosis. McCarron et al (152) investigated the irritative effect of material from the nucleus pulposus upon the dural sac, adjacent nerve roots, and nerve root sleeves independent of the influence of direct compression upon these structures. McCarron (153) further explored epidural fibrosis in an experimental model in adult mongrel dogs. He reported an inflammatory reaction in the spinal cord sections taken from dogs sacrificed after an initial injection of homogenized nucleus pulposus, whereas the spinal cord was grossly normal after an initial injection of normal saline.

Postlaminectomy syndrome, or pain following surgical procedures, including laminectomy, fusion and microsurgical procedures on the lumbar spine, is a common entity in modern medicine (3-6, 19-103). Even though the exact incidence and prevalence of postlumbar laminectomy syndrome is not known, it is estimated to be occasionally as high as $68 \%$.

The recurrence of back or sciatic pain after lumbar surgery may be secondary to a multitude of causes. Various causes for continued pain after lumbar surgery leading to failed back surgery syndrome are epidural fibrosis, true recurrent disc herniation, new disc herniation at a different level, local arachnoiditis, facet joint arthritis, secondary spinal stenosis, instability, and spondylitis or spondylodiscitis $(65,154-156)$. Therefore, epidural fibrosis is a major cause of continued pain following surgical intervention, if not surgical failure. Recurrent disc herniation and new disc herniation at a different disc are considered as major causes of surgical failure. Even though epidural fibrosis is seen as a common phenomenon which contributes to almost $60 \%$ of cases of recurring symptoms in conjunction with instability in postlumbar surgery syndrome, the role of epidural fibrosis as a causative factor of chronic pain or a pain generator has been questioned $(103,153,157-161)$. In spite of the debate, whether epidural fibrosis causes pain or not, it is widely accepted that postoperative scar tissue renders the nerve susceptible to injury (162).

Ross et al (21), in a study of the relationship between peri- dural scar evaluated by magnetic resonance imaging and radicular pain after lumbar discectomy, showed that subjects with extensive peridural scarring were 3.2 times more likely to experience recurrent radicular pain. Parke and Watanable (23) analyzed the frequency and location of lumbar dural adhesions in cadavers with lumbar disc herniation, showing significant evidence of adhesions in $40 \%$ at L4/5 levels, in 36\% at L5/S1 levels, and in $16 \%$ at L3/4 levels. Berger and Davis (41) showed that, in a group of 600 patients with a single operation, periradicular fibrosis was diagnosed preoperatively in $0.67 \%$ and postoperatively in $11 \%$. They also showed that, in 400 patients with multiple operations, at the time of the second operation, the incidence of periradicular fibrosis had risen to $47 \%$. However, epidural adhesions have also been seen without surgery. Leakage of the irritants of the nucleus pulposus into the epidural space has been documented to cause an inflammatory response, resulting in an increase in fibrocytic deposition, which results in epidural fibrosis $(23,109,110$, $118,152,153,157,162-164)$.

Numerous authors $(109,110,118,152,153,163-196)$ have identified the likely role of chemical irritation of the nerve root by the nucleus pulposus. In 1934, Mixter and Barr (197) demonstrated that a herniated disc could cause nerve root encroachment, ultimately producing back pain. Soon after that it was noticed that the removal of the disc did not always result in pain relief (198). In 1951, Barr (199) reported that a patient may have persistent low back pain, sciatica, or both, in spite of surgical intervention. Mixter and Ayers (200) also reported, soon after their discovery of neurocompressive lesion, that low back and leg pain may occur without disc herniation and normal appearance of a disc. Thus, the concept of noncompressive lesion and irritation of the nerve root, as well as the definition of failed back surgery syndrome or postlumbar laminectomy syndrome with persistent or recurring low back pain, with or without radiculitis following one or more lumbar operations, evolved. Various proposed mechanisms for radicular pain include axonal damage, neuroma formation, focal demyelination, intraneural edema, impaired microcirculation, epidural fibrosis and nerve damage. Evidence for the inflammatory mechanism, though, continues to emerge and is convincing.

Epidural fibrosis or arachnoiditis was a relatively rare entity prior to the introduction of lumbar spine surgery for degenerative conditions. Prior to 1935, the condition of chronic adhesional arachnoiditis was generally described as chronic spinal meningitis (157). A multitude of reports in which epidural fibrosis was found at repeat surgery ap- 
parently led to the speculation of the association of recurrent symptomatology with perineural scarring $(157,167$, 201). While the causes of prevalence of failed back syndrome, including epidural scarring, arachnoiditis and mechanical instability, are not accurately known, the prevalence of recurrent disc herniation and facet joint pain in postlumbar laminectomy syndrome was shown to be $5 \%$ to $11 \%$ (58) and $32 \%,(202)$ consecutively.

Kuslich et al (203) concluded that the presence of scar tissue compounded pain associated with the nerve root by fixing it in one position and thus increasing the susceptibility of the nerve root to tension or compression. They also concluded that sciatica can only be reproduced by direct pressure or stretch on the inflammatory, stretched, or compressive nerve root. Even though considerable debate exists as to whether epidural fibrosis causes pain, it is widely accepted that postoperative scar tissue renders the nerves susceptible to injury (162). Scar tissue is generally found in the three compartments of the epidural space. Dorsal epidural scar tissue is formed by resorption of surgical hematoma and may be involved in pain generation (204). In the ventral epidural space, dense scar tissue is formed by ventral defects in the disc, which may persist despite surgical treatment and continue to produce either chronic low back or lower extremity pain after the surgical healing phase (103). Finally, the lateral epidural space includes epiradicular structures out of the root canals, termed sleeves, containing the exiting nerve root and dorsal root ganglia, susceptible to lateral disc defects, facet overgrowth and neuroforaminal stenosis, etc., (205). Thus, it is postulated that various changes producing low back pain and lower extremity pain include inflammation, edema, fibrosis, venous congestion, mechanical pressure on the posterior longitudinal ligament, reduced or absent nutrient delivery to the spinal nerve or nerve root, and central sensitization. It is well known that inflammation may render nociceptors more sensitive to mechanical stimuli (206).

It has been stated that epidural adhesions are not readily diagnosed by conventional studies such as myelography, computerized tomography, and MRI; even though modern technology has made significant improvements in this area (1, 109, 110-118, 164, 206-210). It is believed that epidural adhesions are best diagnosed by performing an epidurogram, which is most commonly performed via the caudal route, followed by the other routes, including the lumbar interlaminar route (110-118, 206-210). Epidural filling defects have also been seen in a significant number of patients with no history of prior surgery (164).
While peridural scarring in itself is not painful, it can produce pain by "trapping" spinal nerves so that movement places tension on the nerves, thus eliciting pain in an inflamed nerve $(112,115,203)$. Kuslich et al (203) reported that back pain was produced by stimulation of several lumbar tissues. However, the outer layer of the anulus fibrosis and posterior longitudinal ligament innervated by synovial vertebral nerves were the most common tissues of origin (112).

\section{RATIONALE}

The rationale for spinal endoscopy and adhesiolysis in the management of chronic, resistant spinal pain stems from the fact that epidural adhesions are a common source of chronic low back pain. The epidural space restricted by adhesions is safely accessible to a fiberoptic endoscope. Removal or correction of structural abnormalities of the lumbar spine may fail to cure and may even worsen painful conditions; degenerative processes of the lumbar spine and the origin of spinal pain are complex; the effectiveness of a large variety of therapeutic interventions in managing low back pain has not been demonstrated conclusively; the reasonable effectiveness of percutaneous adhesiolysis with spring guided catheter has been demonstrated (1); and spinal endoscopy and therapeutic application of drugs in selected cases have been shown to be clinically effective and safe.

Racz et al (115) rationalized percutaneous lysis of epidural adhesions on the basis that inflammation, edema, fibrosis, and venous congestion; mechanical pressure on posterior longitudinal ligaments, annulus fibrosus, and spinal nerve; reduced or absent nutrient delivery to the spinal nerve or nerve root; and central sensitization may be present in patients with chronic back pain and/or radiculopathy. Hence, it is reasonable to treat back pain with or without radiculopathy with local application of anti-inflammatory medication, eg, corticosteroids; agents aimed at reducing edema, eg, hypertonic sodium chloride solution, corticosteroids; local anesthetics, and hyaluronidase to promote lysis (115). Failure of percutaneous lysis of adhesions logically leads to spinal endoscopy with lysis of adhesions, with rationalization of indications for spinal endoscopy, which is less invasive than surgery, spinal cord stimulation and intrathecal delivery systems; but more invasive than percutaneous lysis of adhesions with a spring guided catheter. Spinal endoscopy with adhesiolysis is indicated only with appropriate diagnostic evaluation and after failure or ineffectiveness of other conservative or less invasive modalities of treatment has been proven. 
Table 3. Results of published reports of spinal endoscopy

\begin{tabular}{|c|c|c|c|c|c|c|}
\hline \multirow[b]{2}{*}{ Author(s) } & \multirow[b]{2}{*}{$\begin{array}{c}\text { Study } \\
\text { characteristic }\end{array}$} & \multirow[b]{2}{*}{$\begin{array}{c}\text { Number of } \\
\text { patients }\end{array}$} & \multicolumn{4}{|c|}{ Relief } \\
\hline & & & 1-4 weeks & 3 months & 6 months & 1 year \\
\hline Richardon et al (150) & $\mathrm{P}$ & 34 & Sig & Sig & Sig & Sig \\
\hline Manchikanti et al (145) & $\mathrm{R}$ & 60 & $100 \%$ & $75 \%$ & $40 \%$ & $22 \%$ \\
\hline Manchikanti et al (146) & $\mathrm{R}$ & 85 & $100 \%$ & $77 \%$ & $52 \%$ & $21 \%$ \\
\hline Choi et al (147) & $\mathrm{R}$ & 24 & $66 \%$ & $45 \%$ & $29 \%$ & $29 \%$ \\
\hline
\end{tabular}

While most commonly used methods involve entry into the epidural space through the sacral hiatus, medication placed in the posterior or posterolateral epidural space may not reach pathology in an intravertebral foramen or in the anterior epidural space (171, 211-218). The rationale for the transforaminal approach is based on lesion-specific adhesiolysis and delivery of medication to fulfill the aim of reaching the primary site of pathology, thus improving the ultimate outcome. In fact, present evidence evaluating the effectiveness of transforaminal steroids is encouraging compared to interlaminar and caudal epidural steroid injections (1). While transforaminal endoscopes may be developed in the future, by utilizing the present modality of endoscopic adhesiolysis through the caudal epidural space, it is hoped that the anterior or ventral epidural space is accessed by distension of the epidural space and by mechanical means with steering of the catheter and lysis of adhesions.

Additional aspects of the rationale include the mechanical and hydrostatic effect of the procedure with high volume fluid administration and direct access to the target site, removing or diluting the chemical irritants.

\section{CLINICAL EFFECTIVENESS}

Clinical effectiveness of endoscopic adhesiolysis with direct visualization was evaluated in one prospective case series (150), four retrospective trials (144-147) and some case reports (141-143). The summary of results is shown in Table 3 .

Richardson et al (150) evaluated the role of spinal endoscopy in 34 patients in a prospective case series suffering with chronic, severe low back pain, with $50 \%$ of the patients having failed back surgery syndrome. They reported the presence of epidural adhesions in $100 \%$ of the patients, with $41 \%$ having dense adhesions. A follow-up over a 1year period showed significant reductions in pain scores and disability.

Manchikanti et al (145), in a study evaluating the effectiveness of endoscopic adhesiolysis in postlumbar laminectomy syndrome in 60 patients, showed that $100 \%$ of the patients reported significant pain relief at 1 month, whereas $75 \%$ reported significant relief at 3 months; $40 \%$ reported significant relief at 6 months, and $22 \%$ reported significant relief at 12 months. They concluded that endoscopic adhesiolysis with administration of corticosteroids is a safe and possibly cost-effective technique for relief of chronic intractable pain failing to respond to other modalities of treatments.

Manchikanti et al (146) studied the value and safety of epidural endoscopic adhesiolysis. In a retrospective evaluation of 85 consecutive patients undergoing 112 epidural endoscopic procedures, they reported significant pain relief in $100 \%$ of the patients, initially decreasing to $94 \%$ at 1 to 2 months, to $77 \%$ at 2 to 3 months, to $52 \%$ at 3 to 6 months, to $21 \%$ at 6 to 12 months, and to $7 \%$ after 12 months. They concluded that epidural endoscopy with adhesiolysis is a relatively safe and possibly cost-effective technique in the management of chronic refractory low back pain.

Saberski (144), in a retrospective analysis of spinal endoscopy and laminectomy, reported outcome data in a pilot study that included two groups of patients, Group I, with 22 patients treated via spinal endoscopy; and Group II, with 13 patients treated via laminectomy. After spinal canal endoscopy, only $32 \%$ of Group I patients were continued on opioid medication; whereas $92 \%$ of Group II patients were continued on opioid medication after laminectomy. In addition, $72 \%$ from the spinal canal endoscopy group and only $28 \%$ from the laminectomy group returned 
to work. He concluded that this study suggested remarkable differences in outcomes when comparing patients who underwent spinal canal endoscopy to a similar population who underwent lumbar laminectomy.

Choi et al (147) analyzed back and leg pain and the effectiveness of epiduroscopy and the treatment of failed back pain syndrome retrospectively in 24 patients. All patients failed to respond to a conservative and interventional pain management program including opioids; epidural injections; facet, sacroiliac and nerve root blocks; radiofrequency thermoneurolysis; cryoanalgesia; psychology and extended physiotherapy. All of the patients underwent a caudal epiduroscopy using a percutaneous flexible endoscope to investigate the pathology and an endoscopic epiduroplasty to release the fibrosis and to retrieve the epidural space. Following this, epidural injection with lidocaine and steroids was performed. Patients were followed up for 6 months. The results showed that there were 13 men and 11 women, with a mean age of 49.5 and a range of 28 to 70 years. Mean duration of pain was 7.1 years, with a range of 20 to 30 years. Of the 24 patients, 20 patients had postlumbar laminectomy syndrome. The authors reported that all patients showed inflammation of the epidural contents with loose fibrotic tissue extensively either bilaterally or locally. The preoperative mean visual analog scale score of back pain was 8.0 and relief with VAS less than 4 was obtained within 1 month in 12 patients (50\%, 3 months in 7 patiens, $29 \%$, and 6 months in 3 patients, and 13\%, 4 patients; $16 \%$ reported complete pain relief). Leg pain was relieved in all of the successful patients.

Based on the above, the type and strength of efficacy evidence analysis place spinal endoscopy into type IVlimited, which is defined as evidence from well-designed, nonexperimental studies from more than one center or research group: but this evidence is also complemented by clinical experience (1).

\section{INDICATIONS}

Epiduroscopy or spinal endoscopy is approved in the United States for directed delivery of normal saline and steroid by the Federal Drug Administration. Various devices have been manufactured for this purpose by Visionary Biomedical (Myelotec $®$ ) Clarus $®$ in the mid 1990s and by $\mathrm{EBI} \circledast$ in the year 2000. Spinal canal endoscopy was frequently used for delivery of epidural steroid medication rather indiscriminately; proper indications were not established. By the late 1990s numerous versions of the tech- nique and numerous indications emerged; however, there was no standardized protocol for spinal endoscopy. Although there has not been appropriate peer-reviewed literature basing the evidence on randomized, controlled studies resulting in the decision that this technique was experimental, since then multiple evaluations have appeared in the literature. Concato et al (219) conducted a study of randomized, controlled trials and observational studies using a hierarchy of research designs. They described that, in the hierarchy of research designs, the results of randomized, controlled trials have been considered to be evidence of the highest grade, whereas observational studies have had less validity because such studies reportedly overestimate treatment effects. Concato et al (219) also showed that the average results of the observational studies were remarkably similar to those of randomized, controlled trials; and concluded that the results of well-designed observational studies (with either a cohort or a casecontrolled design) do not systematically overestimate the magnitude of the effects of treatment as compared with those in randomized, controlled trials on the same topic. Yet the medical world continues to focus on randomized, controlled trials. Spinal endoscopy in the mid 1990s began to be used with high expectations, with anticipation of the first phase of the study requiring up to 60 investigators or so. The study was designed to assist the outcome and safety of epidural steroid injections made with fiberoptic endoscopic technique by improving the target delivery of the steroid in patients with persistent lumbar radiculopathy that did not respond to physical therapy or two to three volumetric caudal epidural injections (120). The premise behind the philosophy was that the majority of failures of epidural injections were arising from failure to deliver the injectate to the target area, owing to either a proliferation of connective tissue scar, the presence of fat or perhaps other morphologic anomalies around the nerve roots in question. Once again, the philosophy was based on indications described for nonendoscopic adhesiolysis with a spring guided catheter.

In 1998, an international group of experts drew up a consensus paper establishing a standard for epiduroscopy (120). This panel defined spinal canal endoscopy as "percutaneous, minimally invasive endoscopy investigation of the epidural space to enable color visualization of anatomic structures inside the spinal canal: dura mater, blood vessels, connective tissue, nerves, fat, and pathologic structures, including adhesions, inflammation, and stenotic change." General indications were established for spinal endoscopy and diagnosis and treatment of spinal pain syndromes including: 
1. Observation of pathology and anatomy,

2. Direct drug application,

3. Direct lysis of scarring (with medication, blunt

dissection, laser, and other instruments),

4. Placement of catheter and electrode systems

(epidural, subarachnoid), and

5. An adjunct to minimally invasive surgery.

However, this has been widely ignored in the United States. Indications in the United States include lysis of scarring with drug application under direct visualization. Thus, endoscopy epidural adhesiolysis is indicated in patients with chronic low back pain who have failed to respond to conservative modalities of treatment, including epidural injections administered under fluoroscopic guidance, percutaneous lysis of adhesions with a spring guided catheter, and other well-documented therapeutic modalities. Various conditions in which spinal endoscopy is indicated include postlumbar laminectomy syndrome; epidural adhesions; and disc disruption resulting in chronic, intractable pain nonresponsive to other modalities of treatment. Possible or even probable indications include low back pain nonresponsive to other modalities of treatments and chemical irritation.

Even though indications as described above are commonly utilized, it is of paramount importance that endoscopic lysis of epidural adhesiolysis in management of chronic low back pain should only be performed in patients who are ideal candidates without any major contraindications. It is also important to understand that the response of endoscopic epidural adhesiolysis in managing chronic low back pain secondary to facet joint mediated pain, and degenerative arthritis will be poor due to differing pathophysiology.

Contraindications include but are not limited to coagulopathy, pregnancy, renal insufficiency, chronic liver dysfunction, history of adverse reaction to local anesthetic or anti-inflammatory drugs, history of gastrointestinal (GI) bleeding or ulcers, urinary sphincter dysfunction, progressive neurological deficit, infection, increased intracranial pressure, pseudotumor cerebri, intracranial tumors, unstable angina, severe chronic obstructive pulmonary disease, inability to achieve appropriate positioning, and inability to understand informed consent and protocol. The procedure should never be performed under general anesthesia. Other minor or related contraindications include generalized symptomatology, active untreated or resistant psychiatric disorders affecting the physical condition, and visual deficiencies.

\section{COST EFFECTIVENESS}

Fortunately, the cost effectiveness of spinal endoscopy and adhesiolysis was determined in two separate groups of patients $(145,146)$. In the present environment of healthcare cost explosion, heightened attention to fraud and abuse and rapidly developing new technology, confusion abounds over what is meant by the term cost effectiveness. Cost-minimization analysis, cost-benefit analysis, cost effectiveness analysis (CEA), and cost-utility analysis are multiple terms utilized in describing cost effectiveness. In chronic low back pain CEA would be the most appropriate method to use since in these studies the effects are measured in natural units and quality of life (220-235). The outcome measures used in CEA studies in chronic pain research mainly include functional outcomes, such as disability days saved; pain-free days or improved quality of life; etc.; evaluation of quality of life, which is also known as functional status, health status, or health-related quality of life; well-being of the patient; satisfaction with care; health service utilization/economic analysis, and medical findings (230).

Evaluation in assessment of quality of life focuses on the patient's major perceived functional impairments, and improvement in areas of individual importance such as having sexual relations, returning to work, going to school, homemaking, playing with children/grandchildren, or performing other activities of daily living. These assessments are designed to evaluate functional status in the real world with activities of daily living, rather than being limited to one aspect of life, i.e., return to work, which may or may not be possible due to various reasons, including retirement, long-term disability and other factors. Thus, quality of life is a practical measure in difficult situations, essentially measuring social functioning, along with activities of daily living determining the extent of the improvement in health problems affecting practical aspects of life.

The cost of outpatient treatment programs ranges from $\$ 7,000$ to $\$ 10,000$, whereas the cost of inpatient chronic pain programs ranges from $\$ 17,000$ to $\$ 25,000$ in 1988 dollars (231). Chronic pain patients may also incur health-care bills in excess of $\$ 20,000$ annually for repetitive and, in many cases, redundant diagnostic workups, drugs, and numerous interventions. It was estimated that back pain accounted for 150 million lost workdays in the United States every year, which worked out to be about $\$ 14$ billion in wage costs alone (228). Surprisingly, it was also shown that even a $1 \%$ reduction in overall prevalence could con- 
siderably reduce morbidity and save billions of dollars considering the large magnitude of the back pain problem (228). The cost effectiveness of lumbar discectomy for the treatment of herniated intervertebral discs was published in 1996 (225). The cost effectiveness of lumbar discectomy for the treatment of herniated intervertebral discs has been based on the conclusion that surgery increases the average quality-adjusted life expectancy by 0.43 years during the decade following treatment compared to conservative treatment, a result comparable to extending a healthy life by 5 months. Malter et al (225) concluded that, for carefully selected patients with herniated discs, surgical diskectomy is a cost-effective treatment at a discounted cost of $\$ 12,000$ per diskectomy, or $\$ 29,000$ per life year adjusted for quality. However, this evaluation failed to take into consideration chronic pain patients following surgical treatment for herniated disc. It has been shown that, after the failure of the first surgery, the success of a second operation was only $50 \%$, with an additional $20 \%$ considering themselves worse after surgery (20). However, it is even worse with further surgeries, as with a third procedure, the success rate was $30 \%$, with $25 \%$ considering themselves worse; and, after four surgical interventions, only a $20 \%$ success rate was achieved, with $45 \%$ of these patients considering themselves worse (20). Thus, if additional cost of repeat surgery is taken into consideration, the cost of lumbar surgery will probably be much higher; the same may be applied to inflation.

Kuntz et al (227) found the cost effectiveness of fusion with and without instrumentation for patients with degenerative spondylolisthesis and spinal stenosis to be similar to the cost effectiveness of lumbar laminectomy. They demonstrated that laminectomy with a non-instrumented fusion costs $\$ 56,500$ per quality-adjusted year of life versus laminectomy without fusion. The cost effectiveness ratio of instrument infusion compared with noninstrument infusion was $\$ 3,112,800$, per quality-adjusted year of life (227). They were able to determine a reasonable cost effectiveness of $\$ 82,400$ per quality-adjusted year of life. The proportion of patients experiencing symptom relief after instrument infusion was $90 \%$ as compared with $80 \%$ for patients with noninstrument infusion.

The cost effectiveness of intrathecal therapy in failed back surgery syndrome was also evaluated, with publication of the results in 1999 (226). Authors compared intrathecal therapy with alternative therapies for achieving a defined outcome. They reported the cost of medical management to be $\$ 17,037$ per year or $\$ 1,420$ per month, in contrast to intrathecal morphine delivery, which resulted in lower cumulative 60 -month costs of $\$ 16,579$ per year, and $\$ 1,382$ per month.

The evaluation of cost effectiveness of three routes of epidural injections (blind interlaminar, fluoroscopically directed caudal and transforaminal epidural injections) for the management of low back pain showed the cost effectiveness of transforaminal steroids to be $\$ 2,927$ per year, and that of caudal epidural steroids to be $\$ 3,635$, in stark contrast to blind interlaminar lumbar epidural steroid injections at $\$ 6,024$ per year (212). The cost effectiveness of lumbar facet joint nerve blocks in managing chronic low back pain was shown to be $\$ 3,461$ for 1-year improvement of quality of life (229).

The cost effectiveness of percutaneous lysis of adhesions in three studies $(114,117,145)$ for 1 year of improvement in the quality of life varied from $\$ 2,693$ in a randomized, clinical trial evaluation of 1-day epidural adhesiolysis in management of chronic low back pain in patients who failed to respond to fluoroscopically directed epidural steroid injections who were also demonstrated not to have facet joint mediated pain, to $\$ 5,564$ in chronic low back pain management in patients nonresponsive to numerous other modalities of treatments in an earlier study.

The literature showed the cost effectiveness of medical treatment of hypertension as $\$ 16,330$ for a 60 -year-old man in 1974 (230), whereas treatment of depression with medical therapy is $\$ 11,766$ per year of quality-adjusted life (232). On the same lines, the cost effectiveness of total hip arthroplasty has been shown to be $\$ 61,000$ (233), that of coronary artery bypass grafting for patients with triplevessel coronary artery disease and severe left ventricular function as $\$ 41,800$ (234), and that of surgical repair of a 4$\mathrm{cm}$ abdominal aortic aneurysm as $\$ 21,800$ with improvement per quality-adjusted year of life gained (235).

The cost effectiveness of spinal endoscopy in patients failing to respond to all conservative modalities of treatments including percutaneous lysis with a spring guided catheter, was shown to be $\$ 7020$ to $\$ 8127(145,146)$. Hence, spinal endoscopy with adhesiolysis for persistent low back pain, despite all other less invasive modalities of treatment, is in the approximate range as that of other wellaccepted modalities of treatment. However, it is more than less invasive interventional techniques also well within reasonable limits for present-day cost effectiveness. 


\section{COMPLICATIONS}

The most common and worrisome complications of spinal endoscopy with lysis of adhesions are related to instrumentation and administration of high volumes of fluids, resulting in excessive epidural hydrostatic pressures, which may cause spinal cord compression, excessive intraspinal and intracranial pressures, epidural hematoma, bleeding, infection, increased intraocular pressures with resultant visual deficiencies and even blindness and dural puncture $(110,145,146,233)$. Even though dural puncture was noted in 8 of 112 procedures (146), and 7 of 77 procedures (145), subarachnoid blockade was seen in only $30 \%$ to $40 \%$ of patients, without any other complications. However, excessive pressure development has the potential to affect both local and distant perfusion, possibly resulting in visual changes and even blindness. Even though the incidence is rare, it appears that it would be much higher with spinal endoscopic procedures with a combination of high volumes of fluid and generation of high hydrostatic pressures (236). Their incidence also has been reported with routine epidural injections, presumably resulting from transmission of spinal canal pressures cephalad into the brain while CSF and affecting retinal perfusion or macular hemorrhage.

Kushner and Olson (237) evaluated patients who complained of visual-field defects or blurred vision after receiving epidural steroid injections and concluded that retinal hemorrhage is uncommon but significant, and a previously unemphasized complication of epidural steroid injections in general. Retinal hemorrhages mainly have been attributed to rapid epidural injections of high volumes, causing a sudden increase in intracranial pressure, resulting in the increase of retinal venous pressure (237-243). Hence, it appears that there is a causal relationship between these complications and spinal endoscopy and adhesiolysis with administration of high volumes of saline, and other agents, specifically with rapid injections.

Epidural infection following this procedure is a distinct possibility due to the procedure itself, as well as potential immunosuppression secondary to steroid injection (244284). Manchikanti et al (146) reported a serious infection in one patient requiring prolonged antibiotic therapy and skin grafting in a patient on anticoagulant therapy. Infection also occurred following 2 of 112 procedures. In this evaluation, infection was suspected in 6 of 112 procedures, managed by prophylactic antibiotics (146). Manchikanti et al (145) also reported suspicion of infection following 8 of 77 procedures, with no major complications in another study.
Sampath and Rigamonti (244), in a review of epidemiology, diagnosis, and treatment of spinal epidural abscess, noted that spinal nerve block was responsible for $7 \%$ of the patients, whereas a multitude of predisposing factors included intravenous (IV) drug use, diabetes neuritis, multiple medical illnesses, trauma, prior spinal surgery, morbid obesity, HIV disease, and end-stage renal disease in a descending order of frequency. Wang et al (245), in a 1-year study of the incidence of spinal epidural abscess after epidural analgesia, reported 9 cases of epidural abscess formation from a total of 17,372 epidural catheters. Rathmell et al (246) discussed various aspects of epidural abscess following epidural analgesia.

Direct trauma to the spinal cord following spinal endoscopy in the lumbar spine is only a theoretical possibility. Neural trauma is a potential complication, even though there are no such case reports. Subdural injection, neural trauma, injury to the spinal cord, and hematoma formation have been described with epidural injections, even though there are no specific descriptions relating to spinal endoscopy (285-289). Spinal gas collection and subdural intracranial air were also reported following epidural injections (290-292). Lumbar radiculopathy has been reported following intraspinal gas collection not associated with herniated discs (293-297). Neurological complications of spinal and epidural anesthesia were reviewed by Horlocker and Wedel (287). They reported a $0.2 \%$ to $2.9 \%$ cardiac arrest rate, $0.2 \%$ to $1.2 \%$ death rate, $0.4 \%$ to $3.6 \%$ neurological injury rate, 0.5 to $3.8 \%$ radiculopathy rate, $0 \%$ to $1.2 \%$ incidence of cauda equina syndrome and $0 \%$ to $1.8 \%$ incidence of paraplegia after reviewing 30,413 epidurals. They also reported anterior spinal artery syndrome leading to spinal cord ischemia resulting in flaccid paralysis of the lower extremities (298). Transient and neurologic symptoms after epidural analgesia also have been reported, including cauda equina syndrome (299).

Epidural hematoma following epidural analgesia in a patient receiving unfractionated heparin for thromboprophylaxis (288) and paraplegia after epidural anesthesia in a patient with peripheral vascular disease with the development of hematoma (289) have been reported. Cauda equina syndrome secondary to idiopathic spinal epidural lipomatosis also has been reported (300). However, spinal cord trauma or spinal cord or epidural hematoma formation is a catastrophic complication possible with spinal endoscopic adhesiolysis, although there are no case reports in the literature. Other potential complications include increased or continued pain, transient dysesthesias, paresis, paralysis, local surgical site bleed- 
ing, allergic reactions, and side effects related to the administration of steroids. While paresis, paralysis, and intractable pain may be related to needle trauma, epidural hematoma, elevated hydrostatic pressures, ischemia, or nerve injury; severe headache, dysesthesia and intractable acute back pain may indicate epidural hematoma, cord ischemia, and elevated hydrostatic pressure. However, the safety of steroids and preservatives at epidural therapeutic doses has been demonstrated in both clinical and experimental studies (301-317). The major theoretical complications of corticosteroid administration include arachnoiditis, suppression of the pituitary-adrenal axis, hypocorticism, Cushing's syndrome, osteoporosis, avascular necrosis of bone, steroid myopathy, weight gain, fluid retention, and hyperglycemia $(316,317)$. Other potential complications include hypertension, hypokalemia, epidural lipomatosis, retinal hemorrhage, subcapsular cataract formation, insomnia, mood swings, psychosis, facial flushing, headache, GI disturbances, and menstrual disturbances. However, the use of corticosteroids repeatedly for days or even a few weeks does not lead to adrenal insufficiency upon cessation of treatment; but prolonged therapy with corticosteroids occasionally may result in the suppression of pituitary-adrenal function that can be slow in returning to normal. Rare hypothalamic-pituitary-adrenal suppression during corticosteroid administration with epidural injections and after its withdrawal has been reported (316-319). However, no such reports have implicated spinal endoscopy and administration of steroids. Manchikanti et al (320) evaluated the effect of neuraxial steroids on weight and bone mass density (BMD) prospectively. They studied 204 patients, with 123 patients completing the study. They divided the patients into two groups, with one group receiving neural blockade without any steroids and the second group receiving neuraxial steroids. The results of serial determination of weight and BMD showed no significant change at any interval or at the end of 1 year in all 123 patients with or without steroid administration. In addition, this study also showed some improvement in BMD, as well as weight reduction, indicating improvement in functional status. They concluded that low-dose administration of neuraxial steroids is safe in patients suffering with chronic pain who have failed to respond to conservative modalities of treatment with a favorable risk-benefit ratio, without any deleterious effects either on body weight or BMD.

\section{TECHNICAL CONSIDERATIONS}

Spinal endoscopy is best performed by a caudal approach based on anatomy, equipment, and experience with epidu- ral adhesiolysis with spring guided catheter. The straight entry into the epidural space through the caudal approach is much easier and more practical rather than entry into the lumbar epidural space through a paramedian approach, even with a steep angle. This facilitates not only the easy passage of the fiberoptic endoscope but also reduces damage to the device.

\section{Anatomy}

The spinal canal extends from the foramen magnum to the sacrum, which is bounded posteriorly by the ligamentum flavum and periosteum and anteriorly by the posterior longitudinal ligament that lies over the dorsal aspects of the vertebral bodies and discs (120). The size of the spinal canal is variable, with its largest diameter in the cervical and lumbar regions, corresponding to enlargements in the spinal cord measuring $18 \mathrm{~mm}$ in the anterior, posterior dimension at $\mathrm{C} 4$ to 6 , with a transverse diameter of $30 \mathrm{~mm}$; measuring $17 \mathrm{~mm}$ in both anterior, posterior and transverse measurements in the thoracic region, and $23 \mathrm{~mm}$ in anterior posterior diameters and $18 \mathrm{~mm}$ in the transverse diameter in the lumbar region (120). However, the size of the spinal canal is approximately twice the size of the cord. The canal in cross section appears triangular in the lumbar region (120). While the spinal cord ends at L1, the dural sac continues to the spinal cord and conus, running down to the level of S2.

The dural sac rests on the floor of the vertebral canal (321). The anterior relations of the dural sac, therefore, are the backs of the vertebral bodies and the intervertebral discs, and covering these structures is the posterior longitudinal ligament (321). Thus, anterior spinal arteries and sinuvertebral nerves run across the floor of the vertebral canal and are located anterior to the dural sac. The dural sac, posteriorly is related to the roof of the vertebral canal, the laminae, and ligamentum flava (321).

The epidural space is the space intervening between the dural sac and the osseo-ligamentous boundaries of the vertebral canal, which is a narrow space. This is described as a potential space and the term epidural region has been advocated as an alternative description to avoid the connotation of a wide, empty space (322). The epidural space is principally filled by a thin layer of areolar connective tissue which varies from diaphanous to pseudomembranous in structure (322). This also has been described as an epidural membrane (323). The membrane surrounds the dural sac and lines the deep surface of the laminae and pedicles (321). Ventrally, opposite the vertebral bodies, 
the membrane lines the back of the vertebral body and then passes medially deep to the posterior longitudinal ligament, where it detaches to the anterior surface of the deep portion of the ligament (323). However, the membrane does not cover the back of the anulus fibrosus; prevented from doing so by the posterior longitudinal ligament as it expands laterally over the back of the disc. Thus, the epidural membrane blends with the upper and lower borders of the anulus fibrosis, however, in a plane just anterior to that of the posterior longitudinal ligament. Further, the membrane is drawn laterally to form a circumneural sheath around the dural sleeve of the nerve roots and spinal nerve, opposite the intervertebral foramen (323). Anterior and posterior internal vertebral venus plexuses run within the areolar tissue of the epidural membrane (321). Epidural fat is not distributed uniformly throughout the epidural space, but is concentrated around the nerve roots in the intervertebral foramina and in collections wrapped in areolar tissue enlarged in the midline recesses between the ligamentum flavum at each segmental level (322). The size of the posterior epidural space, however, averages only 4 to $6 \mathrm{~mm}$ at the lumbar level, 3 to $5 \mathrm{~mm}$ at the thoracic level, and $2 \mathrm{~mm}$ at the cervical level (120). Thus, the contents of the epidural space include the vertebral venous plexus, the spinal branches of the segmental arteries, the lymphatics, and the dura arachnoid projections that surround the spinal nerve roots, along with abundant fat (120).

\section{Technique}

Prior to undergoing spinal endoscopy, outpatients must be assessed with a comprehensive physical and psychological evaluation. All less invasive and conservative modalities of treatment, including fluoroscopically directed epidural steroid injections and spring guided catheter lysis of adhesions, should be exhausted. In addition, appropriate laboratory studies should be considered to rule out bleeding disorders. Nonsteroidal anti-inflammatory drugs, aspirin, and anticoagulants should be discontinued prior to spinal canal endoscopy to avoid unusual bleeding.

Under the preoperative preparation, an antibacterial scrub with a shower the night before should be considered. In addition, the patient should have an empty stomach. No general anesthesia should be contemplated. The patient should understand all the implications of the procedure and sign an informed consent.

After the initial evaluation, the patient is transferred to the holding area, where appropriate preparation is carried out with preoperative evaluation, checking of vital signs and establishment of IV access, as well as antibiotic administration.

Following this, the patient is taken to the operating room or a sterile procedure room where preparation is carried out with Betadine ${ }^{\circledR}$ prep. Draping is carried out to cover the entire patient, extending into the cervical region.

At this time, under appropriate monitoring with blood pressure and pulse oximetry, sedation is administered and continuous monitoring is performed.

The procedure is performed in a sterile operating room under appropriate sterile precautions using fluoroscopy. The fluoroscope is adjusted over the lumbosacral region to perform the procedure in the lumbosacral region for a lumbar or caudal procedure, both an anteroposterior and lateral views.

After appropriate positioning of fluoroscopy, a physician, scrubbed and with sterile gown and gloves, infiltrates the area for needle insertion with local anesthetic. Following this, an epidural needle is introduced into the epidural space using fluoroscopic visualization. Once the needle placement is confirmed to be in the epidural space, a lumbar epidurogram is carried out using approximately 2 to $5 \mathrm{cc}$ of contrast. Finding the filling defects by examining the contrast flow into the nerve roots is the purpose of the epidurogram. Intravascular or subarachnoid placement of the needle or contrast is avoided; if such malpositioning occurs, the needle is repositioned.

A 0.9-mm guide wire is inserted through the needle, which is advanced under fluoroscopic guidance to the level of suspected pathology, followed by a small incision and advancement of a 2-mm x 17.8-cm dilator with catheter (sheath) over the guidewire. Once the catheter is advanced to the tip of the guidewire, the wire is removed. At this time, a 0.8$\mathrm{mm}$ fiberoptic spinal endoscopy is introduced into the catheter through the valve and is advanced until the tip is positioned at the distal end of the catheter, as determined by video and fluoroscopic images. In conjunction with gentle irrigation using normal saline, the catheter and fiberoptic myeloscope are manipulated and rotated in multiple directions, with visualization of the nerve roots at various levels. Gentle irrigation may also be carried out by slow, controlled infusion. Adhesiolysis and decompression are carried out by distension of the epidural space with normal saline and by mechanical means using the fiberoptic endoscope. Figures. 1 to 4 illustrate the procedural considerations. 


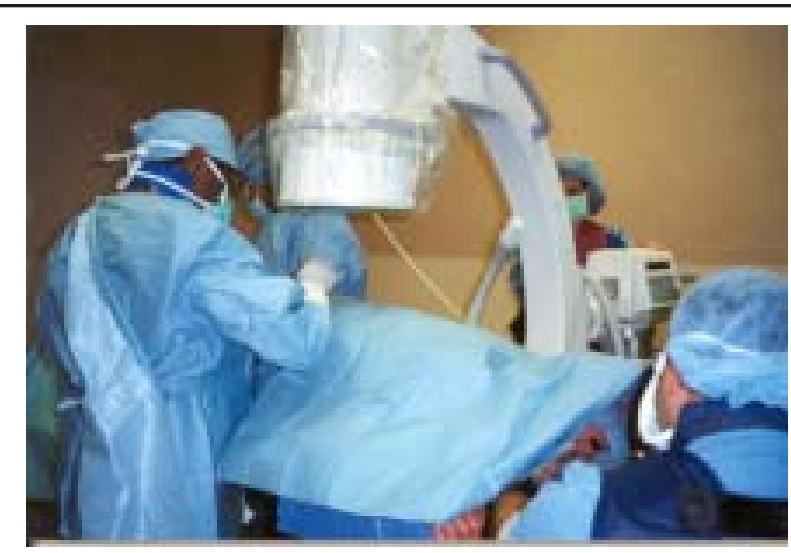

A. Sterile preparation and initiation of Spinal endoscopy

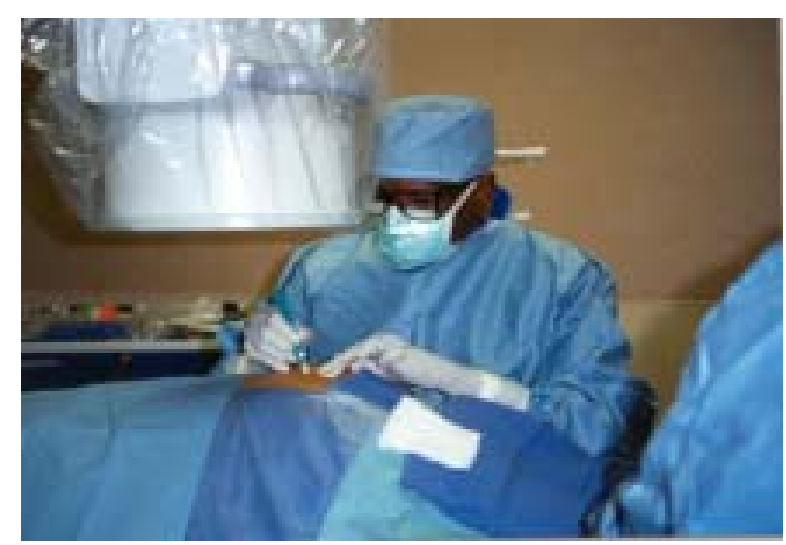

C. A small incision (stab wound) made with a \#11 blade

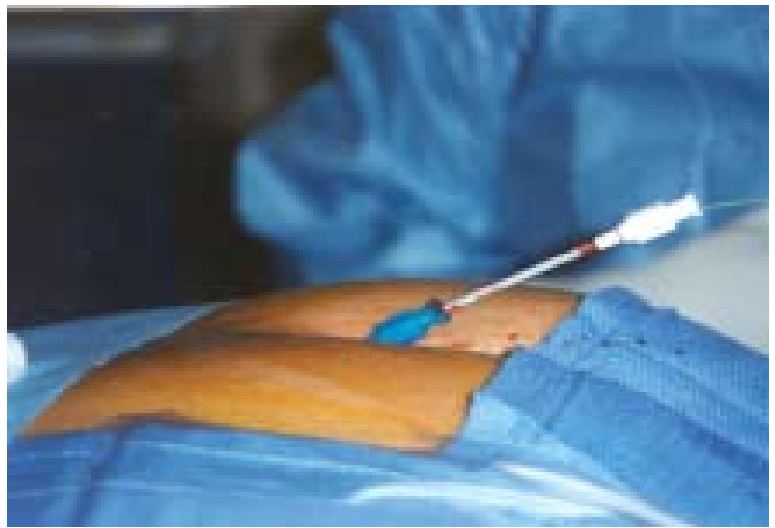

E. Removal of dilator and guide wire - with catheter (sheath) in epidural space

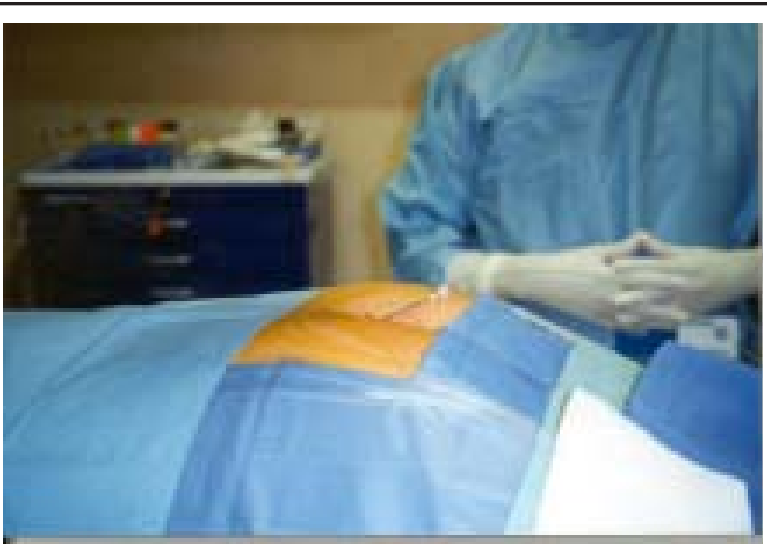

B. Introduction of needle and guide wire through the needle

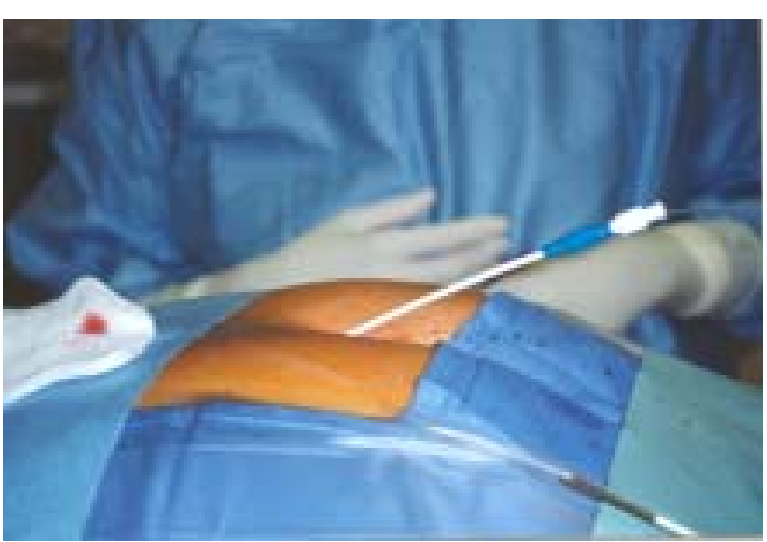

D. Introduction of dilator and catheter (sheath) over guide wire

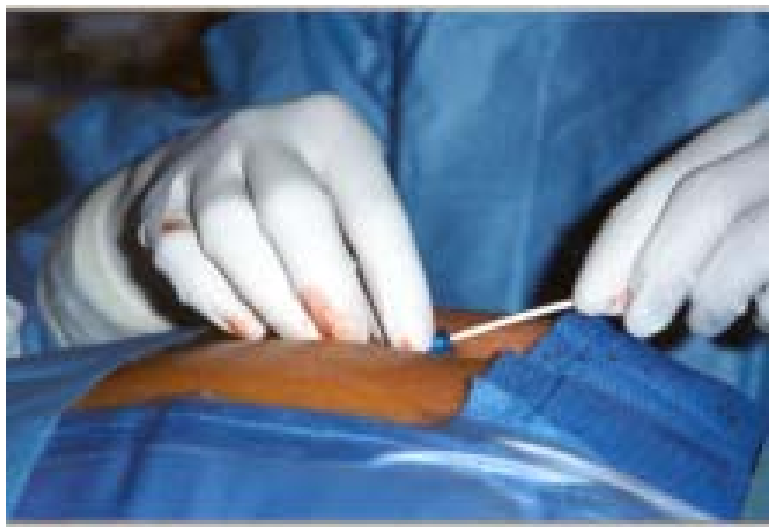

F. Introduction of Fiberoptic Spinal endoscope into the catheter (sheath)

Fig. 1. Spinal endoscopy performed in a sterile operation room 


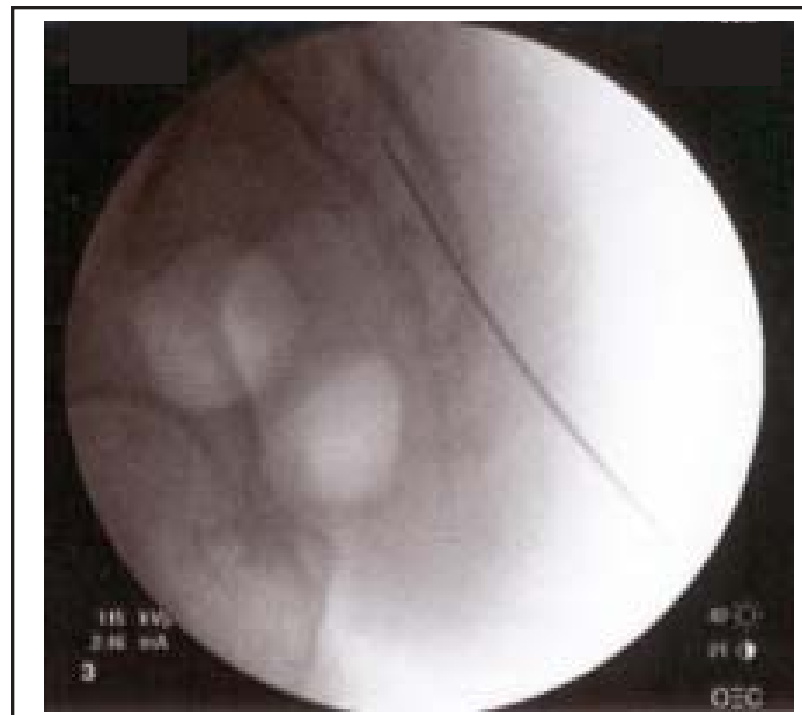

A. Lateral view epidural needle inside the sacral canal

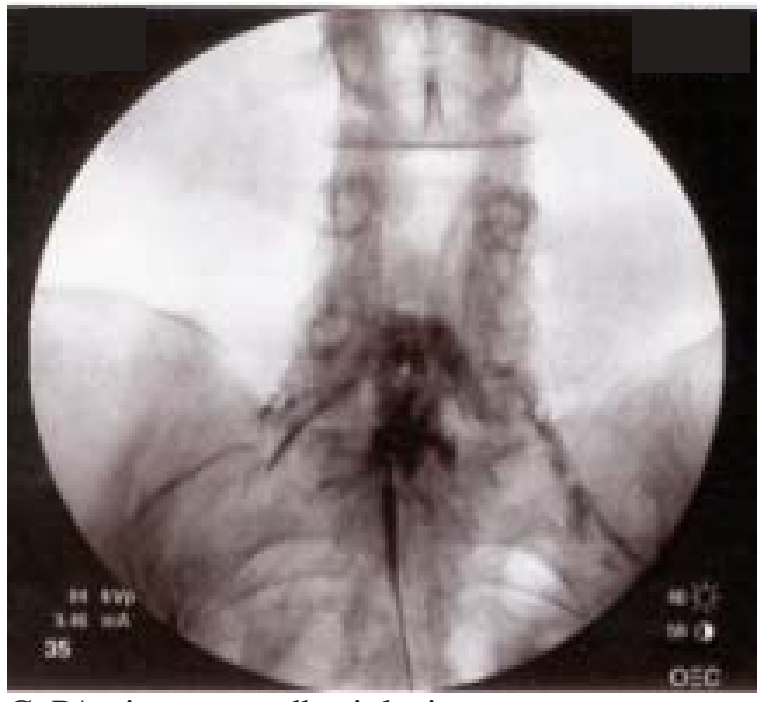

C. PA view post-adhesiolysis

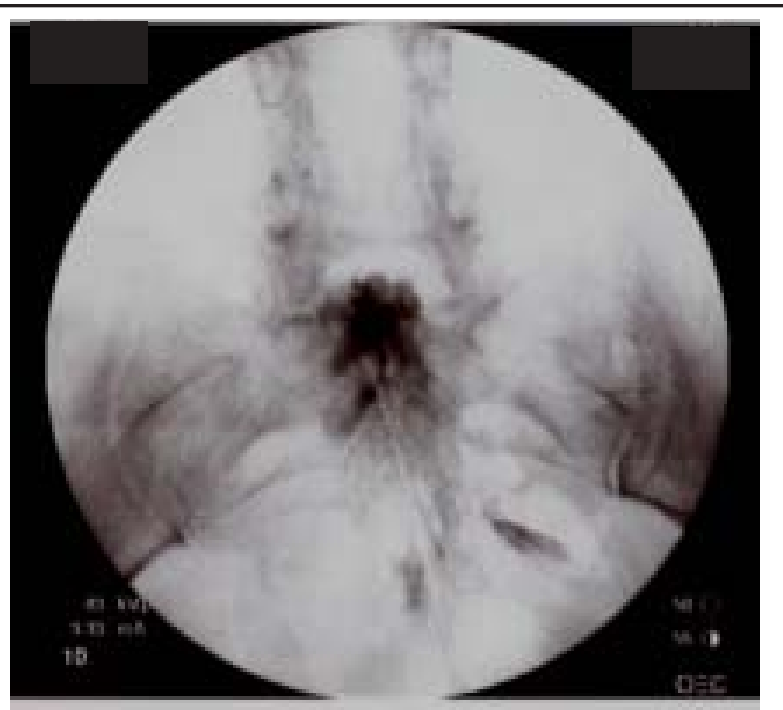

B. PA view, showing filling defect

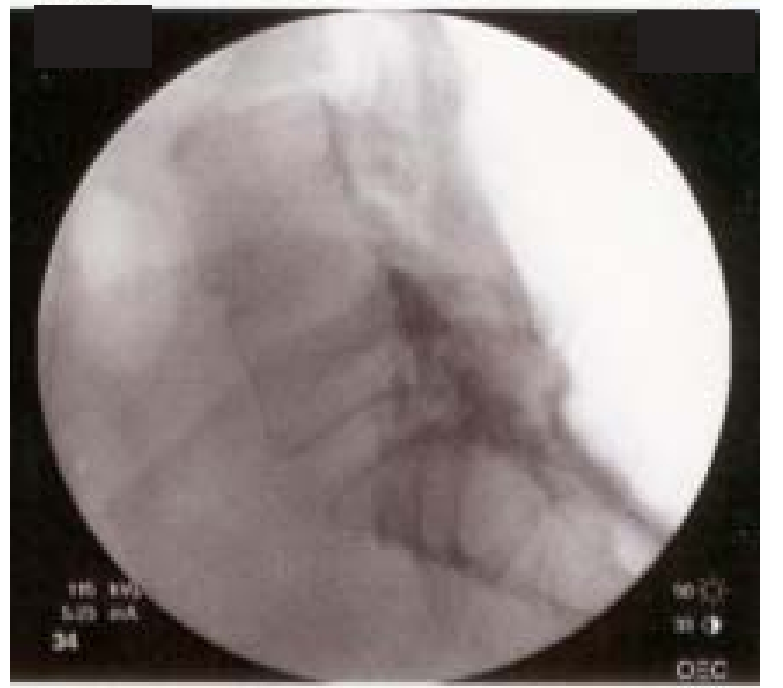

D. Lateral view post-adhesiolysis

Fig 2. Flouroscopic visualization of needle placement and lumbar epidurography

Confirmation is accomplished with injection of non-ionic contrast material. An epidurogram is performed on at least two occasions. Following completion of the procedure, generally, lidocaine $1 \%$, preservative free, mixed with 6 to $12 \mathrm{mg}$ of betamethasone acetate and phosphate mixture or methylprednisolone or triamcinolone is injected in each case after assuring that there is no evidence of subarachnoid leakage of contrast. If there is a question of subarachnoid leakage of the contrast, a Racz catheter may be passed into the epidural space, and a mixture of local anesthetic injected very slowly in incremental doses, followed by injection of the steroid.

Following completion of the procedure, if necessary, selfabsorbed sutures are applied, followed by sterile Bioclusive ${ }^{\circledR}$ dressing. Subsequently, the patient is turned to the supine position and transferred to the recovery room. In the recovery room, the patient is very closely monitored for any potential complications or side effects. If a patient 


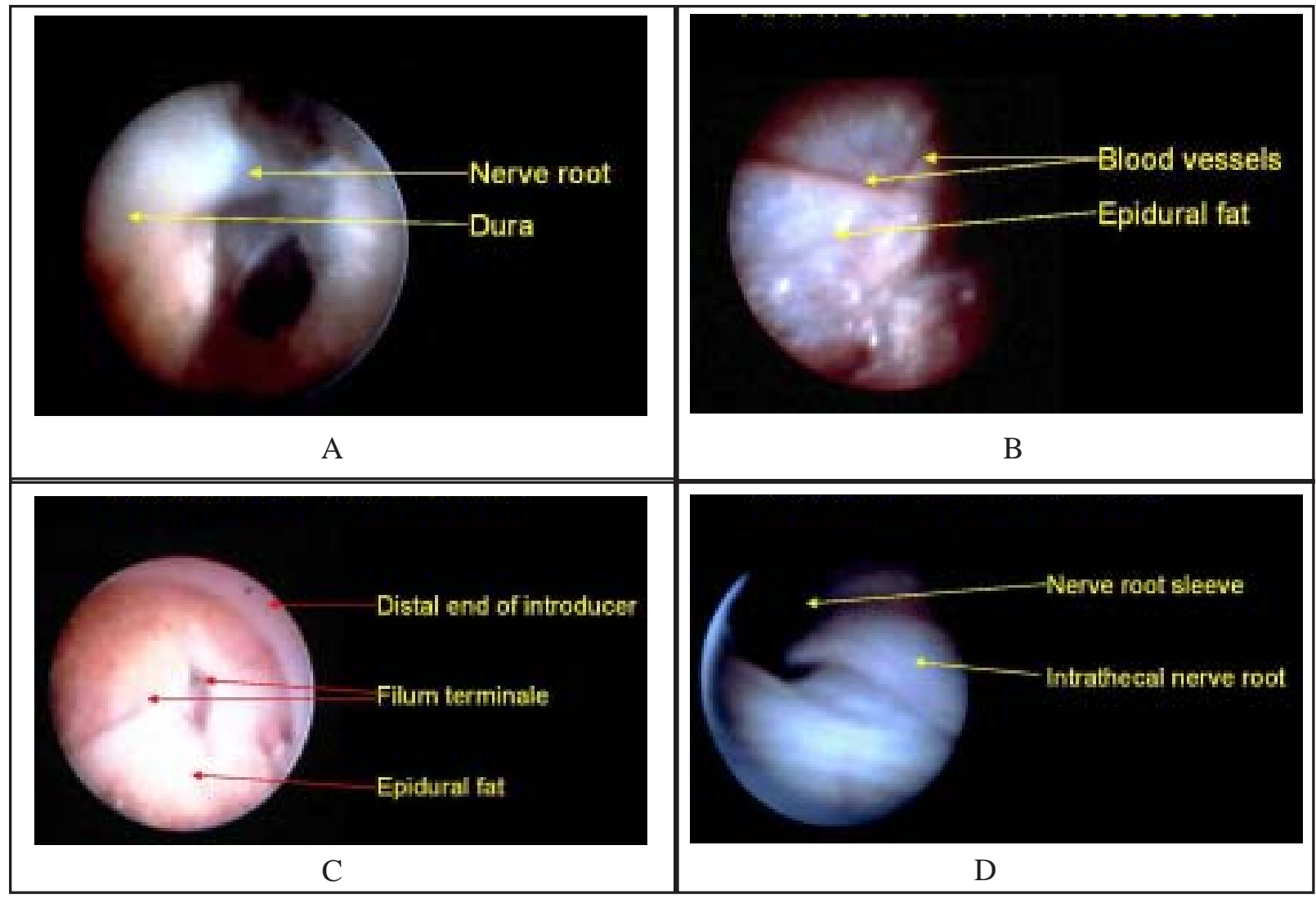

Fig. 3. Normal endoscopic anatomy of lumbar epidural space Reproduction with permission from Visionary Biomedical (Mylotec), Inc.

has a catheter and no complications are observed and good pain relief is reported without any motor weakness, steroid is injected. At times, subsequent hypertonic saline neurolysis is also carried out with $10 \%$ sodium chloride solution.

Following this, the patient is re-evaluated, the catheter is flushed with normal saline and the catheter, if present, is removed and checked for intactness. The wound is also checked at this time, with or without the catheter. The patient is ambulated if all parameters are satisfactory and IV access is removed, and the patient is discharged home with appropriate instructions.

\section{CONCLUSION}

Chronic low back pain is a major health care and social problem. Much of the confusion surrounding endoscopic adhesiolysis in managing refractory low back pain results from overemphasis on biopsychosocial problems and inappropriate selection of patients for this treatment modality. Considering the preliminary cumulative evidence available in the literature on endoscopic epidural adhesiolysis, the efficacy of this procedure is similar, if not superior, to various other modalities of treatments available in managing chronic low back pain, including surgical intervention.

While this is a very effective technique in managing chronic low back pain, caution must be exercised, as there are significant risks of complications of spinal cord trauma. While a pain practitioner needs to individualize the choice of treatment to each patient and personal experience, we recommend endoscopic epidural adhesiolysis, which has proven to be a valuable, safe, and cost-effective technique for relieving chronic, intractable pain nonresponsive to all other conservative modalities of treatment when performed in an outpatient setting, with reasonable and customary charges for the facility and physician services. 


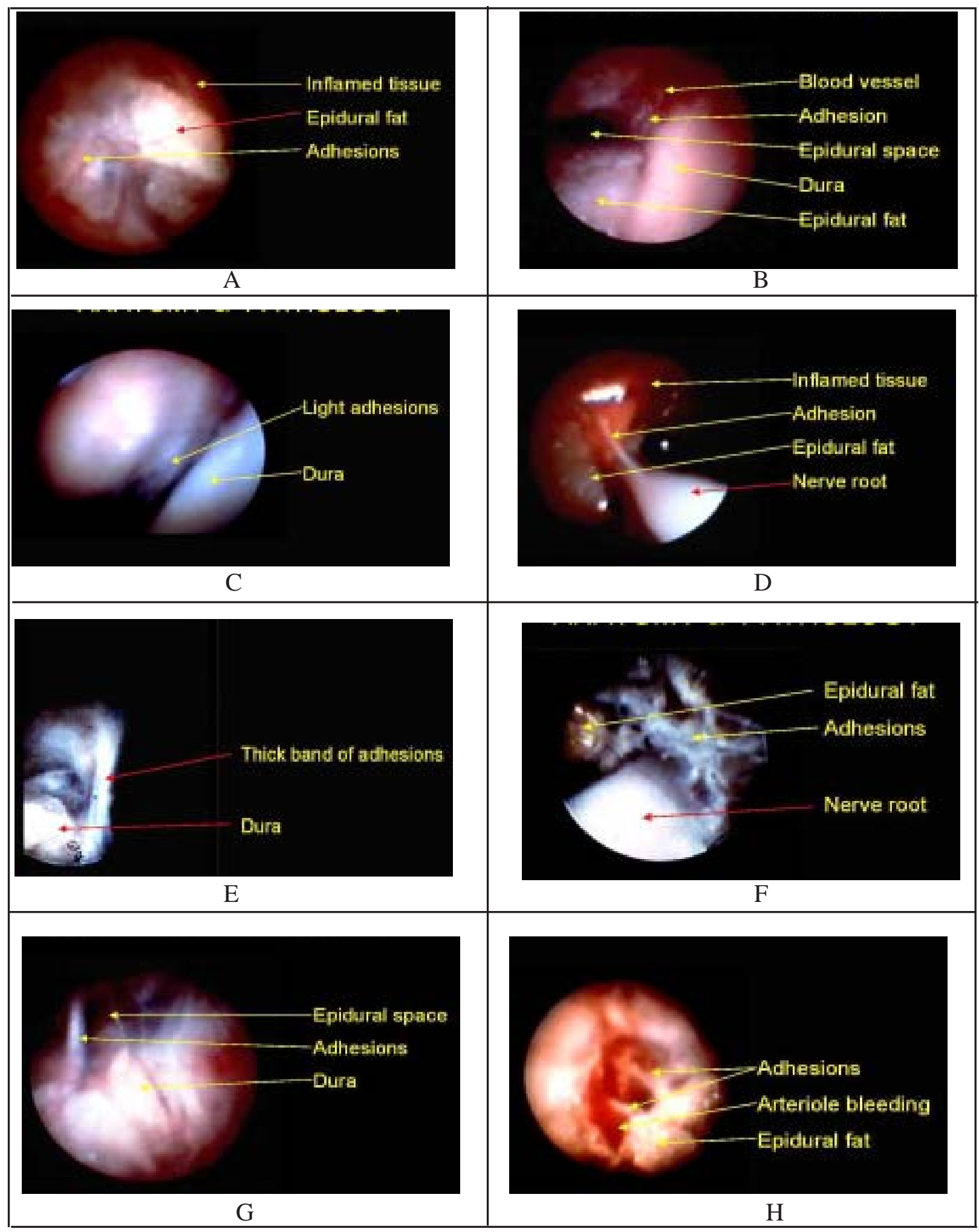

Fig. 4. Typical findings of endoscopic anatomy and adhesiolysis of lumbar epidural space Reproduction with permission from Visionary Biomedical (Mylotec), Inc. 


\section{ACKNOWLEDGMENTS}

The authors wish to thank Denise Pratt and Tonie Hatton for their dedication and patience in the preparation of this manuscript.

\section{REFERENCES}

1. Manchikanti L, Singh V, Kloth D et al. Interventional techniques in the management of chronic pain: Part 2.0. Pain Physician 2001; 4:24-96.

2. Manchikanti L. The role of neural blockade in the management of chronic low back pain. Pain Digest 1999; 9:166-181.

3. Wilkinson HA. Introduction: Etiology, diagnosis, and therapy. In The Failed Back Syndrome. Etiology and Therapy, Second Edition. Springer-Verlag, New York, 1992, pp 1-3.

4. Wilkinson HA. The role of improper surgery in the etiology of the failed back syndrome. In The Failed Back Syndrome. Etiology and Therapy, Second Edition. Springer-Verlag, New York, 1992, pp 4-12.

5. Nachemson AL. Failed back surgery syndrome is syndrome of failed back surgeons. Pain Clinic 1999; 11:271284.

6. North RB. Management of the failed back surgery syndrome. Adv Oper Ortho 1993; 161-173.

7. Lawrence RC, Helmick CG, Arnett FC. Estimates of the prevalence of arthritis and selected musculoskeletal disorders in the United States. Arthritis \& Rheumatism 1998; 41:778-799.

8. Manchikanti L. Chronic low back pain in the elderly: Part I. Am J Pain Manage 1997;7:104-117.

9. Cassidy D, Carroll L, Cote P: The Saskatchewan Health and Back Pain Survey. Spine 1998;23:1860-1867.

10. Van Den Hoogen HJM, Koes BW, Deville W et al. The prognosis of low back pain in general practice. Spine 1997;22:1515-1521.

11. Croft PR, Macfarlane GJ, Papageorgiou AC et al. Outcome of low back pain in general practice: A prospective study. Brit Med J 1998;316:1356-1359.

12. Andersson GBJ, Svensson HO. The intensity of work recovery in low back pain. Spine 1983; 8:880-887.

13. Davis H. Increasing rates of cervical and lumbar spine surgery in the United States, 1979-1990. Spine 1994;19:1117-1124.

14. Gureje O, Von Korff M, Simon GE et al. Persistent pain and well-being: A World Health Organization study in primary care. JAMA 1998;280:147-151.

15. Miedema HS, Chorus AMJ, Wevers CWJ et al. Chronicity of back problems during working life. Spine 1998; 18:2021-2029.

16. Carey TS, Garrett JM, Jackman A et al. Recurrence and care seeking after acute back pain: Results from a long-term follow-up study. Medical Care 1999; 2:157164.
17. Hagen KB, Thune O. Work incapacity from low back pain in the general population. Spine 1998; 19:20912095.

18. Leigh JP, Markowitz SB, Fahs M et al. Occupational injury and illness in the United States: Estimates of costs, morbidity, and mortality. Arch Intern Med 1997; 157:1557-1568.

19. Turner JA, Ersek M, Herron L et al. Surgery for lumbar spinal stenosis, attempted meta-analysis of the literature. Spine 1992;17:1-7.

20. Waddell G, Kummel EG, Lotto WN et al. Failed lumbar disc surgery and repeat surgery following industrial injury. J Bone Joint Surg (Am) 1969;61:201-207.

21. Ross JS, Robertson JT, Frederickson RCA et al. Association between peridural scar and recurrent radicular pain after lumbar discectomy: Magnetic resonance evaluation. Neurosurgery 1996;38:855-863.

22. Fritsch EW, Heisel J, Rupp S. The failed back surgery syndrome. Reasons, intraoperative findings, and longterm results: A report of 182 operative treatments. Spine 1996;21:626-633.

23. Parke WW, Watanable R. Adhesions of the ventral lumbar dura. Adjunct source of discogenic pain? Spine 1990; 15:300-303.

24. Quiles M, Marchisello PJ, Tsairis P. Lumbar adhesive arachnoiditis: Etiological and pathological aspects. Spine 1978; 3:45-50.

25. Benoist M, Ficat C, Baraf P et al. Post operative lumbar epiduroarachnoiditis: Diagnostic and therapeutic aspects. Spine 1980; 5:432-436.

26. Fager CA, Freidberg SR. Analysis of failures and poor results of lumbar spine surgery. Spine 1980; 5:87-94.

27. Hanley EN, Shapiro DE. The development of low back pain after excision of a lumbar disc. J Bone Joint Surg 1989; 71A:719-721.

28. Frymoyer JW. Magnitude of the problem. In Weinstein J, Weisel SW (eds). The Lumbar Spine. Philadelphia, WB Saunders, 1990, pp 32-38.

29. LaRocca H. Failed lumbar surgery. Principles of management. In Weinstein J, Wiesel S (eds). The Lumbar Spine. WB Saunders Company, Philadelphia, 1990, pp 872-881.

30. Rutkow IM. Orthopaedic operations in the United States, 1979-1983. J Bone Joint Surg 1986; 68A: 716719.

31. Hanley EN Jr. The cost of surgical intervention for lumbar disc herniation. In Weinstein JN (ed). Clinical Efficacy and Outcome in the Diagnosis and Treatment of Low Back Pain. Raven Press, New York, 1992, pp 125-133.

32. Burton CV. Causes of failure of surgery on the lumbar spine: Ten-year follow up. Mt Sinai J Med 1991; 58:183-187.

33. Burton CV, Kirkaldy-Nillis WH, Yong-Hing K et al. Causes of failure of surgery on the lumbar spine. Clin Orthop 1981; 157:191-199. 
34. North RB, Campbell JN, James CS et al. Failed back surgery syndrome: 5 year follow-up in 102 patients undergoing repeated operation. Neurosurgery 1991; 28:685-691.

35. Katz JN, Lipson SJ, Larson MG. The outcome of decompressive laminectomy for degenerative lumbar spinal stenosis. J Bone Joint Surg 1991; 73:809-816.

36. Postacchini F. Results of surgery compared with conservative management for lumbar disc herniations. Spine 1996; 21:1383-1387.

37. Law JD, Lehman RAW, Kirch WM. Reoperation after lumbar intervertebral disc surgery. J Neurosurg 1978;48:259-263.

38. Waddell G, Gibson NA, Grant I. Surgical treatment of lumbar disc prolapse and degenerative lumbar disc disease. In Nachemson AL, Jönsson E (eds). Neck and Back Pain. Lippincott Williams \& Wilkins, Philadelphia, 2000, pp 305-325.

39. Gibson JNA, Grant IC, Waddell G. The Cochrane review of surgery for lumbar disc prolapse and degenerative lumbar spondylosis. Spine 1999; 24:1820-1832.

40. Keskimaki I, Seitsalo S, Osterman Het al. Reoperations after lumbar disc surgery. A population-based study of regional and interspecialty variations. Spine 2000; 25:1500-1508.

41. Berger E, Davis JMB. Chronic pain following lumbar spinal surgery in 1000 patients. Proceedings of $9^{\text {th }}$ World Congress on Pain, August 1999, pp181-182.

42. Elzayat, SG, Faanaos C, Elzayat IM. Failed back surgery: A prospective study. J Neurol Orthop Med Surg 1995; 16:165-166.

43. Cinotti G, David T, Postacchini F. Results of disc prosthesis after a minimum follow-up period of 2 years. Spine 1996; 21:995-1000.

44. Johnsson KE, Alfudén, Rosén I. The effect of decompression on the natural course of spinal stenosis. A comparison of surgically treated and untreated patients. Spine 1991; 16:615-619.

45. Horenstein S. Chronic low back pain and the failed low back syndrome. Neurol Clin 1989; 7:361-385.

46. Jönsson B, Strömqvist B. Clinical characteristics of recurrent sciatica after lumbar discectomy. Spine 1996; 21:500-505.

47. Taylor VM, Deyo RA, Ciol M et al. Patient-oriented outcomes from low back surgery. Spine 2000; 25:24452452.

48. Atlas SJ, Keller RB, Robson D et al. Surgical and nonsurgical management of lumbar spinal stenosis. Four-year outcomes from the Maine lumbar spine study. Spine 2000; 25:556-562.

49. Frocrain L, Duvauferrier R, Husson JL et al. Recurrent postoperative sciatica: Evaluation with MR imaging and enhanced CT. Radiology 1989; 170:531-533.

50. Fountas KN, Kapsalaki EZ, Johnston KW et al. Postoperative lumbar microdiscectomy pain. Minimilization by irrigation and cooling. Spine 1999; 24:1958-1960.
51. Postacchini F. Lumbar disc herniation. A new equilibrium is needed between nonoperative and operative treatment. Spine 2001; 26:601.

52. Yorimitsu E, Chiba K, Toyama Y et al. Long-term outcomes of standard discectomy for lumbar disc herniation. A follow-up study of more than 10 years. Spine 2001; 26:652-657.

53. DeBerard MS, Masters KS, Colledge AL. Outcomes of posterolateral lumbar fusion in Utah patients receiving workers' compensation. A retrospective cohort study. Spine 2001; 26:738-747.

54. Kuslich SD, Danielson G, Dowdle JD et al. Four-year follow-up results of lumbar spine arthrodesis using the Bagby and Kuslich lumbar fusion cage. Spine 2000; 25:2656-2662.

55. Hu RW, Jaglal S, Axcell T et al. A population-based study of reoperations after back surgery. Spine 1997; 22:2265-2271.

56. Wetzel FT, LaRocca H. The failed posterior lumbar interbody fusion. Spine 1991; 16:839-845.

57. Katz J. Lumbar spinal fusion. Surgical rates, costs, and complications. Spine 1995; 20:78S-83S

58. Suk KS, Lee HM, Moon SH et al. Recurrent lumbar disc herniation. Results of operative management. Spine 2001;26:672-676.

59. Junge A, Fröhlich M, Ahrens S et al. Predictors of bad and good outcome of lumbar spine surgery. A prospective clinical study with 2 years' follow-up. Spine 1996; 21:1056-1065.

60. Katz J, Lipson S, Chang L et al. Seven- to 10-year outcome of decompressive surgery for degenerative lumbar spinal stenosis. Spine 1996; 21:92-98.

61. Biondi J, Greenberg BJ. Redecompression and fusion in failed back syndrome patients. J Spinal Disord 1990; 3:362-369.

62. Wetzel FT, Phillips FM, Aprill CN. Extradural sensory rhizotomy in the management of chronic lumbar radiculopathy. Spine 1997; 22:2283-2292.

63. Herno A, Airaksinen O, Saari T et al. Surgical results of lumbar spinal stenosis. A comparison of patients with or without previous back surgery. Spine 1995; 20:964-969.

64. Loupasis GA, Stams K, Katonis PG et al. Seven-to 20-year outcome of lumbar discectomy. Spine 1999; 24:2313-2317.

65. Crock HV. Observation on the management of failed spinal operations. J Bone Joint Surg 1976; 58:193199.

66. Greenwood J, McGuire TH, Kimbell F. A study of the causes of failure in the herniated intervertebral disc operation: An analysis of sixty-seven reoperated cases. J Neurosurg 1952; 9:15-20.

67. Barrios C, Ahmed M, Arrotegui JI et al. Clinical factors predicting outcome after surgery for herniated lumbar disc: An epidemiological multivariate analysis. J Spinal Disord 1990; 3:205-209. 
68. Matsui H, Terahata N, Tsuji H et al. Familial predisposition and clustering for juvenile lumbar disc herniation. Spine 1992; 17:1323-1328.

69. Pheasant HC. Sources of failure in laminectomies. Orthop Clin North Am 1975; 6:319-329.

70. Connolly ES. Surgery for recurrent lumbar disc herniation. Clin Neurosurg 1992; 39:211-216.

71. Fandino J, Botana C, Viladrich A et al. Reoperation after lumbar disc surgery: Results in 130 cases. Acta Neurochir Wien 1993; 122:102-104.

72. Jackson RK. The long-term effects of wide laminectomy for lumbar disc excision: A review of $130 \mathrm{pa}-$ tients. J Bone Joint Surgery 1971; 53:609-616.

73. Jönsson B, Stromqvist B. Repeat decompression of lumbar nerve roots: A prospective two-year evaluation. J Bone Joint Surg 1993; 75:894-897.

74. Thomalske G, Galow W, Ploke G. Critical comments on a comparison of two series (1000 patients each) of lumbar disc surgery. Adv Neurosurg 1977; 4:22-27.

75. Bernard TN. Repeat lumbar spine surgery: Factors influencing outcome. Spine 1993; 18:2196-2200.

76. Ebeling U, Kalbaryck H, Reulen HJ. Microsurgical reoperation following lumbar disc surgery: Timing, surgical findings, and outcomes in 92 patients. $J$ Neurosurg 1989; 70:397-404.

77. Epstein JA, Lavine LS, Epstein BS. Recurrent herniation of the lumbar intervertebral disc. Clin Orthop 1967; 52:169-178.

78. O'Sullivan MG, Connolly AE, Buckley TF. Recurrent lumbar disc protrusion. Br J Neurosurg 1990; 4:319-325.

79. Barr JS, Kubik CS, Molloy MK et al. Evaluation of end results in treatment of ruptured lumbar intervertebral discs with protrusion of nucleus pulposus. Surg Gynec and Obstret 1967; 125:250-256.

80. Frymoyer JW, Hanley EN, Howe J et al. Disc excision and spine fusion in the management of lumbar disc disease. A minimum ten-year follow-up. Spine 1978; 3:1-6.

81. Mannismaki P, Vanharanta H, Puranen J. Disability 20-30 years after disc surgery. A follow-up of 162 patients. Presented at the Annual Meeting of the International Society for the Study of the Lumbar Spine, Marseilles, June 15-19, 1993.

82. Naylor A. Late results of laminectomy for lumbar disc prolapse. A review after ten to twenty-five years. $J$ Bone Joint Surg 1974; 56:17-29.

83. Salenius P, Laurent LE. Results of operative treatment of lumbar disc herniation. A survey of 886 patients. Acta Orthop Scand 1977; 48:630-634.

84. Davis RA. A long-term outcome analysis of 984 surgically treated herniated lumbar discs. J Neurosurg 1994; 80:415-421.

85. Dvorak J, Gauchat MH, Valach L. The outcome of surgery for lumbar disc herniation. A 4 to 17 -year follow-up with emphasis on somatic aspects. Spine 1988; 13:1418-1422.
86. Nashold BS Jr., Blaine S, Hrubec Z. Lumbar Disc Disease. A Twenty-Year Clinical Follow-up Study. C.V. Mosby Co., St. Louis, 1971.

87. O'Connell JEA. Protrusions of the lumbar intervertebral discs. A clinical review based on five hundred cases treated by excision of the protrusion. J Bone Joint Surg 1951; 33:8-30.

88. Shannon N, Paul EA. L4/5 and L5/S1 disc protrusions: Analysis of 323 cases operated on over 12 years. $J$ Neurol Neurosurg Psychiatry 1979; 42:804-809.

89. Spangfort EV. The lumbar disc herniation: A computer aided analysis of 2,504 operations. Acta Orthop Scand 1972; 142(Suppl):1-95.

90. Waddell G, Reilly S, Torsney B et al. Assessment of the outcome of low back surgery. J Bone Joint Surg 1988; 70:723-727.

91. Weber H. Lumbar disc herniation. A controlled, prospective study with ten years of observation. Spine 1983; 8:131-140.

92. Deyo RA, Cherkin DC, Loeser JD et al. Morbidity and mortality in association with operations on the lumbar spine. J Bone Joint Surg 1992; 74A:536-544.

93. Rosenstein C, Hardy RW Jr. Repeat operations for lumbar disc. In Hardy RW Jr. (ed). Lumbar Disc Disease, Second edition. Raven Press, New York, 1993, pp 171-177.

94. Korres DS, Loupassis G, Stamos K. Results of lumbar discectomy: A study using 15 different evaluation methods. Eur Spine J 1992; 1:20-24.

95. Kelley JH, Voris DC, Svien HJ et al. Multiple operations for protruded intervertebral disc. Proc Staff Meet Mayo Clin 1954; 29:546-550.

96. Boccanera L, Davalli C, Laus M. Multiple operations on the lumbar spine: A study of 15 patients operated on 3 times or more for an initial diagnosis of prolapsed disc. Ital J Orthop Traumatol 1984; 10:321-331.

97. Finnegan WJ, Fenlin JM, Marvel JP et al. Results of surgical intervention in the symptomatic multiply-operated back patient. J Bone Joint Surg 1979; 61:10771082 .

98. Lehmann TR, LaRocca HS. Repeat lumbar surgery: A review of patients with failure from previous lumbar surgery treated by spinal canal exploration and lumbar spinal fusion. Spine 1981; 6:615-619.

99. Stauffer RN, Coventry MB. A rational approach to failures of lumbar disc surgery: The orthopedist's approach. Orthop Clin North Am 1971; 2:533-542.

100. Weir BKA, Jacobs GA. Reoperation rate following lumbar discectomy: An analysis of 662 lumbar discectomies. Spine 1980; 5:366-370.

101. Herno A, Airaksinen O, Saari T. Long-term results of surgical treatment of lumbar spinal stenosis. Spine 1993; 11:1471-1474.

102. Pappas CT, Harrington T, Sonntag VK. Outcome analysis in 654 surgically treated lumbar disc herniations. Neurosurgery 1992; 30:862-866. 
103. Anderson S. A rationale for the treatment algorithm of failed back surgery syndrome. Curr Rev Pain 2000; 4:395-406.

104. Pasquier NM, Leri D. Injection-intra-et extraudrales de cocaine a dose minime daus le traitment de la sciatique. Bull Gen Ther 1901; 142:196.

105. Caussade G, Queste P. Traitement de al neuralgia sciatique par la mèthode de Sicard. Résultats favorables même dans les cas chroniues par la cocaïne à doses élevées et répétées à intervalles raproches. Bull Soc Med Hosp Paris 1909; 28:865.

106. Sicard JA, Forestier J. Méthode radiographique d'exploration de la cavité épidurale par le Lipiodol. Rev Neurol 1921; 28:1264-1266.

107. Ombregt L, Ter Veer HJ. Treatment of the lumbar spine. In Omebregt L, Bisschop P, Ter Veer HJ et al (eds). A System of Orthopaedic Medicine. WB Saunders, London, 1995, pp 633-688.

108. Brown JH. Pressure caudal anesthesia and back manipulation. Northwest Med 1960; 59: 905-909.

109. Racz GB, Holubec JT. Lysis of adhesions in the epidural space. In Racz GB (ed). Techniques of Neurolysis. Kluwer Academic, Boston, 1989, pp 57-72.

110. Racz GB, Sabonghy M, Gintautas J et al. Intractable pain therapy using a new epidural catheter. JAMA 1982; 248: 579-581.

111. Racz GB, Haynsworth RF, Lipton S. Experiences with an improved epidural catheter. Pain Clinic 1986; $1: 21-27$

112. Racz GB, Heavner JE, Raj PP. Percutaneous epidural neuroplasty. Prospective one-year follow up. Pain Digest 1999; 9:97-102.

113. Heavner JE, Racz GB, Raj P. Percutaneous epidural neuroplasty. Prospective evaluation of $0.9 \% \mathrm{NaCl}$ versus $10 \% \mathrm{NaCl}$ with or without hyaluronidase. Reg Anesth Pain Med 1999; 24:202-207.

114. Manchikanti L, Pakanati R, Bakhit CE et al. Role of adhesiolysis and hypertonic saline neurolysis in management of low back pain. Evaluation of modification of Racz protocol. Pain Digest 1999; 9:91-96.

115. Racz GB, Heavner JE, Raj PP. Epidural neuroplasty. Seminars in Anesthesia 1997; 302-312.

116. Manchikanti L, Bakhit CE. Percutaneous lysis of epidural adhesions. Pain Physician 2000; 3:46-64.

117. Manchikanti L, Pampati V, Fellows B et al. Role of one day epidural adhesiolysis in management of chronic low back pain: A randomized clinical trial. Pain Physician 2001; 4:153-166.

118. Lou L, Racz G, Heavner J. Percutaneous epidural neuroplasty. In Waldman SD (ed) Interventional Pain mManagement, Second Edition, W.B. Saunders Company, Philadelphia, 2000, pp 434-445.

119. Saberski L, Brull S. Spinal and epidural endoscopy: A historical review. Yale J Bio Med 1995: 68:7-15.

120. Saberski LR. Spinal endoscopy current concepts. In Waldman SD (ed) Interventional Pain Management, Second Edition, W.B. Saunders Company, Philadel- phia, 2000, pp 143-161.

121. Burman MS. Myeloscopy or the direct visualization of the spinal cord. J Bone Joint Surg 1931; 13:695696.

122. Shimoji K, Fujoka H, Onodera M et al. Observation of spinal canal and cisternae with the newly developed small-diameter, flexible fiberscopes. Anesthesiology 1991; 75:341-344.

123. Stern EL. The spinascope: A new instrument for visualizing the spinal canal and its contents. Medical Record (NY) 1936; 143:31-32.

124. Pool JL. Direct visualization of dorsal nerve roots of the cauda equina by means of a myeloscope. Arch Neurol 1938; 39:1308-1312.

125. Pool JL. Myeloscopy: Diagnostic inspection of the cauda equina by means of an endoscope. Bull Neurol Inst. 1938; 7:178-189.

126. Pool JL. Myeloscopy: Intraspinal endoscopy. Surgery $1942 ; 11: 169-182$.

127. Ooi Y, Morisaki N. Intrathecal lumbar endoscope. Clin Orthopedic Surgery (Japan) 1969; 4:295-297.

128. Ooi Y, Satoh Y, Morisaki N. Myeloscopy. Igakuno Ayumi (Japan) 1972; 81:209-212.

129. Ooi Y, Satoh Y, Morisaki N. Myeloscopy. Orthop Surg (Japan) 1973; 24:181-186.

130. Ooi Y, Satoh Y, Morisaki N. Myeloscopy: Possibility of observing lumbar intrathecal space by use of an endoscope. Endoscopy 1973; 5:91-96.

131. Ooi Y, Satoh Y, Morisaki N. Myeloscopy: A preliminary report. J. Japan. Orthop Assoc 1973; 47:619-627.

132. Ooi Y, Satoh Y, Morisaki N. Myeloscopy. Int. Orthop 1977; 1:107-111.

133. Ooi Y, Satoh Y, Hirose K et al. Myeloscopy. Acta Orthop Belg 1978; 44:881-894.

134. Satoh Y, Hirose K, Ooi Y et al. Myeloscopy in the diagnosis of low back pain syndrome. Proceedings of Third Congress of International Rehabilitation Medicine Assoc, Basel, Switzerland, July 2-9, 1978.

135. Ooi Y, Satoh Y, Inoue K et al. Myeloscopy with special reference to blood flow changes in the cauda equina during Lasegue's test. Int Orthop 1981; 4:307-311.

136. Blomberg RG. A method of epiduroscopy and spinaloscopy: Presentation of preliminary results. Acta Anaesthesiol Scand 1985; 29:113-116.

137. Blomberg RG, Olsson SS. The lumbar epidural space in patients examined with epiduroscopy. Anesth Analg 1989; 68:157-160.

138. Blomberg RG. Technical advantages of the paramedian approach for lumbar epidural puncture and catheter introduction. A study using epiduroscopy in autopsy subjects. Anaesthesia 1988; 43:837-843.

139. Heavner JE, Cholkhavatia S, Kizelshteyn G. Percutaneous evaluation of the epidural and subarachnoid space with the flexible fiberscope. Reg Anesth 1991; 15S1:85. 
140. Heavner J, Chokhavatia K, McDaniel K et al. Diagnostic and therapeutic maneuvers in the epidural space via a flexible endoscope (abstract 1534). In Abstracts of the Seventh World Congress on Pain, Paris (Raven Press), August 1993.

141. Saberski L, Kitahata L. Direct visualization of the lumbosacral epidural space through the sacral hiatus. Anesth Analg 1995; 80:839-840.

142. Saberski L, Kitahata L. Review of the clinical basis and protocol for epidural endoscopy. Connecticut Medicine 1996; 60:71-73.

143. Saberski L, Kitahata L. Persistent radiculopathy diagnosed and treated with epidural endoscopy. J Anesth 1996; 10:292-295.

144. Saberski L. A retrospective analysis of spinal canal endoscopy and laminectomy outcomes data. Pain Physician 2000; 3:193-196.

145. Manchikanti L, Pampati V, Bakhit CE et al. Nonendoscopic and endoscopic adhesiolysis in post lumbar laminectomy syndrome: A one-year outcome study and cost effective analysis. Pain Physician 1999; 2:5258 .

146. Manchikanti L. The value and safety of epidural endoscopic adhesiolysis. Amer J Anesthsiol 2000; 275278.

147. Choi YK, Tan MH, Barbella JD et al. Epiduroscopic analysis of persistent back and leg pain and the efficacy of epiduroscopy in the treatment of failed back pain syndrome. Reg Anesth Pain Med 2001; 26:90.

148. Shutse G, Kurtse G, Grol O et al. Endoscopic method for the diagnosis and treatment of spinal pain syndromes. Anesteziol Reanimatol 1996; 4:62-64.

149. Witte H, Hellweg S, Witte B et al. Epiduroscopy with access via the sacral canal. Some constructional equipment requirements from the anatomic and biomechanical viewpoint. Biomed Tech 1997; 42:24-29.

150. Richardson J, McGurgan P, Cheema S et al. Spinal endoscopy in chronic low back pain with radiculopathy: A prospective case series. Anaesthesia 2001; 56:454-460.

151. LaRocca H, Macnab I. The laminectomy membrane: Studies in its evolution, characteristics, effects and prophylaxis in dogs. J Bone Joint Surg 1974; 5613:545550 .

152. McCarron RF, Wimpee MW, Hudkins PG et al. The inflammatory effect of the nucleus pulposus. A possible element in the pathogenesis of low back pain. Spine 1987; 12:760-764.

153. McCarron RF. Epidural fibrosis: Experimental model and therapeutic alternatives. In Racz GB (ed). Techniques of Neurolysis. Kluwer Academic Publishers, Boston, 1989, pp 87-94.

154. Dahmen G. Rezidivoperationen nacnNucleotomie. Bericht uber ein Kolloquium. In Schollner D (ed). Rezidive Nach Lumbalen Bandscheibenoperationen: Ursachen, Diagnostik, Behandlung. Medizinisch
Literarische Verlags Gesellschaft, Uelzen, Germany 1980, pp70-72.

155. Keyl W, Wirth CJ. Indikation, Technik und Ergebnisse der Operationen bei Nucleusrezidiven. In Schöllner D (ed). Rezidive nach lumbalen Bandscheibenoperationen: Ursachen, Diagnostik, Behandlung. Medizinische Literarische Verlags Gesellschaft, Uelzen, Germany 1980, pp 70-72.

156. Krämer J. Bandscheibenbedingte Erkrankungen: Ursachen, Diagnose, Behandlung, Vorgeugung, Begutachtung, Second edition. Stuttgart, Thieme, 1986.

157. Pawl RP. Arachnoiditis and epidural fibrosis: The relationship to chronic pain. Curr Rev of Pain 1998; 2:93-99.

158. Van Goethem JW, Van de Kelft E, Biltjes IG et al. MRI after successful lumbar discectomy. Neuroradiology 1996; 38:S90-96.

159. Grave P, Tullberg T, Rydberg J et al. Postoperative lumbar magnetic resonance imaging with contrast enhancement: Compression between symptomatic and asymptomatic patients. Acta Radiol 1996; 37:366372.

160. Annertz M, Jönsson B, Stromquist B et al. No relationship between epidural fibrosis and sciatica in the lumbar postdiscectomy syndrome: A study with contrast-enhancement magnetic resonance imagery in symptomatic and asymptomatic patients. Spine 1995; 20:449-453.

161. Cervellini P, Curri D, Volpin L et al. Computed tomography of epidural fibrosis after discectomy. A comparison between symptomatic and asymptomatic patients. Neurosurgery 1988; 6:710-713.

162. Songer M, Ghosh L, Spencer D. Effects of sodium hyaluronate on peridural fibrosis after lumbar laminectomy and discectomy. Spine 1990; 15:550-554.

163. Cooper R, Freemont A, Hoyland J et al. Herniated intervertebral disc-associated periradicular fibrosis and vascular abnormalities occur without inflammatory cell infiltration. Spine 1995; 20:591-598.

164. Manchikanti L, Bakhit CE, Pampati V. Role of epidurography in caudal neuroplasty. Pain Digest 1998; 8:277-281.

165. Olmarker K, Rydevik B. Selective inhibition of tumor necrosis factor- $\alpha$ prevents nucleus pulposus-induced thrombus formation, intraneural edema, and reduction of nerve conduction velocity. Spine 2001; 26:863-869.

166. Olmarker K, Rydevik B, Holm B et al. Effects of experimental graded compression on blood flow in spinal nerve roots: A vital microscopic study on the porcine cauda equina. J Orthop Res 1989; 7:817-823.

167. Cook SD, Prewett AB, Dalton JE et al. Reduction in perineural scar formation after laminectomy with Polyactive ${ }^{\circledR}$ membrane sheets. Spine 1994; 19:18151825.

168. Manchikanti L. Transforaminal lumbar epidural steroid injections. Pain Physician 2000; 3:374-398. 
169. Saal JS, Franson RC, Dobrow R et al. High levels of inflammatory phospholipase A2 activity in lumbar disc herniations. Spine 1990; 15:674-678.

170. Kayama S, Konno S, Olmarker K et al. Incision of the annulus fibrosus induces nerve root morphologic, vascular, and functional changes. Spine 1996;21:25392543.

171. Chaoyang C, Cavanaugh JM, Ozaktay C et al. Effects of phospholipase $\mathrm{A}_{2}$ on lumbar nerve root structure and function. Spine 1997;22:1057-1064.

172. Bobechko WT, Hircsch C. Autoimmune response to nucleus pulposus in the rabbit. J Bone Joint Surg 1965; 47B:574-580.

173. Elves MW, Bucknill T, Sullivan MF. In vitro inhibition of leucocyte migration in patients with intervertebral disc lesions. Orthop Clin North Am 1975; 6:5965.

174. Gertzbein SD. Degenerative disk disease of the lumbar spine: Immunological implications. Clin Orthop 1977; 129:68-71.

175. Gertzbein SD, Tait JH, Devlin SR. The stimulation of lymphocytes by nucleus pulposus in patients with degenerative disk disease of the lumbar spine. Clin Orthop 1977; 123:149-154.

176. Gertzbein SD, Tile M, Gross A. Autoimmunity in degenerative disc disease of the lumbar spine. Orthop Clin North Am 1975;6:67-73.

177. Olmarker K, Blomquist J, Stromberg J et al. Inflammatogenic properties of nucleus pulposus. Spine 1995; 20:665-669.

178. Cavanaugh JM, Ozaktay AC, Vaidyanathan S. Mechano- and chemosensitivity of lumbar dorsal roots and dorsal root ganglia: An in vitro study. Trans Orthop Res Soc 1994; 19:109.

179. Kawakami M, Weinstein JN, Tamaki, et al. The difference in nociceptive potential of the nucleus pulposus and the anulus fibrosus. In Weinstein JN, Gordon SL (eds). Low Back Pain: A Scientific and Clinical Overview. American Academy of Orthopaedic Surgeons, Rosemont, IL, 1996, pp 209-213.

180. Kawakami M, Tamaki T, Weinstein JN et al. Pathomechanism of pain-related behavior produced by allografts of intervertebral disc in the rat. Spine 1996; 21:2101-2107.

181. Kang JD, Georgescu HI, McIntyre-Larkin L et al. Herniated lumbar intervertebral discs spontaneously produce matrix metalloproteinases, nitric oxide, interleukin-6, and prostaglandin E2. Spine 1996; 21: 271-277.

182. Olmarker K, Rydevik B, Nordborg C. Autologous nucleus pulposus induces neurophysiologic and histologic changes in porcine cauda equina nerve roots. Spine 1993; 181:1425-1432.

183. Gronblad M, Virri J, Tolonen J et al. A controlled immunohistochemical study of inflammatory cells in disc herniation tissue. Spine 1994; 19:2744-2751.
184. Jaffray D, O’Brien JP. Isolated intervertebral disc resorption: A source of mechanical and inflammatory back pain? Spine 1986; 11:397-401.

185. Kawakami M, Tamaki T, Hashizume $\mathrm{H}$ et al. The role of phospholipase A2 and nitric oxide in pain-related behavior produced by an allograft of intervertebral disc material to the sciatic nerve of the rat. Spine 1997; 22:1074-1079.

186. Marshall LL, Trethewie ER, Curtain CC. Chemical radiculitis: A clinical, physiological and immunological study. Clin Orthop 1977; 129:61-67.

187. Murphy RW. Nerve roots and spinal nerves in degenerative disk diseases. Clin Orthop 1977; 129:46-60.

188. Nygaard OP, Mellgren SI, Osterud B. The inflammatory properties of contained and noncontained lumbar disc herniation. Spine 1997; 22:2484-2488.

189. Yabuki S, Kikuchi S, Olmarker K et al. Acute effects of nucleus pulposus on blood flow and endoneurial fluid pressure in rat dorsal root ganglia. Spine 1998; 23:25172523.

190. Yabuki S, Igarashi T, Kikuchi S. Application of nucleus pulposus to the nerve root simultaneously reduces blood flow in dorsal root ganglion and corresponding hindpaw in the rat. Spine 2000; 25:1471-1476.

191. Devor M. Pain arising from the nerve root and the dorsal root ganglia and chronically injured axons: A physiological basis for the radicular pain of nerve root compression. Pain 1977; 3:25-41.

192. Olmarker K, Rydevik B, Holm S. Edema formation in spinal nerve roots induced by experimental, graded compression: An experimental study on the pig cauda equina with special reference to differences in effects between rapid and slow onset of compression. Spine 1989; 14:569-573.

193. Yoshizawa H, Nakai S, Koboyashi S et al. Intraradicular edema formation as a basic factor in lumbar radiculopathy. In Weinstein JN, Gordon SL (eds). Low Back Pain: A Scientific and Clinical Overview. American Academy of Orthopaedic Surgeons, Rosemont, IL 1996, pp 235-246.

194. Yabuki S, Onda A, Kikuchi S et al. Prevention of compartment syndrome in dorsal root ganglia caused by exposure to nucleus pulposus. Spine $2001 ; 26: 870-$ 875.

195. Takebayashi T, Cavanaugh J, Ozaktay A et al. Effect of nucleus pulposus on the neural activity of dorsal root ganglion. Spine 2001; 26:940-945.

196. Olmarker K. Mechanical and biochemical injury of spinal nerve roots: An experimental perspective. In Weinstein JN, Gordon SL (eds). Low Back Pain: A Scientific and Clinical Overview. Rosemont, IL, American Academy of Orthopaedic Surgeons, 1996, pp 215233.

197. Mixter WJ, Barr JS. Rupture of the intervertebral disc with involvement of the spinal cord. $N$ Engl J Med 1934; 211:210-215. 
198. Ford LT, Lam RL. The psychiatric aspects of low back pain. J Bone Joint Surg 1952; 38:931-932.

199. Barr JS. Low back pain and sciatic pain. J Bone Joint Surg 1951; 33:633-649.

200. Mixter WJ, Ayers JB. Herniation or rupture of the intervertebral disc into the spinal canal. NEngl J Med 1935; 213:385-395.

201. Barsa JE, Charlton JE. Diagnosis of epidural scarring and its possible contribution to chronic low back pain syndrome. Pain 1984; S4:376.

202. Manchikanti L, Pampati V, Baha AG et al. Contribution of facet joints to chronic low back pain in postlumbar laminectomy syndrome: A controlled comparative prevalence evaluation. Pain Physician 2001; 4:175-180.

203. Kuslich SD, Ulstrom CL, Michael CJ. The tissue origin of low back pain and sciatica. Orthop Clin North Am 1991; 22:181-187.

204. Key JA, Ford LT. Experimental intervertebral disc lesions. J Bone Joint Surg 1948; 30:621-630.

205. Imai S, Hukuda S, Maeda T. Dually innervating nociceptive networks in the rat lumbar posterior longitudinal ligaments. Spine 1995; 19:2086-2092.

206. Racz GB, Noe C, Heavner JE. Selective spinal injections for lower back pain. Curr Rev Pain 1999; 3:333341.

207. Hatten HP Jr. Lumbar epidurography with metrizamide. Radiology 1980; 137:129-136.

208. Roberson GH, Hatten HP Jr, Hesselink JH. Epidurography. Selective catheter technique and review of 53 cases. Am J Radiol 1979; 132:787-793.

209. Stewart HD, Quinnell RC, Dann N. Epidurography in the management of sciatica. Br J Rheumatol 1987; 26:424-429.

210. Devulder J, Lutgarde B, Castille F et al. Relevance of epidurography and epidural adhesiolysis in chronic failed back surgery patients. Clin J Pain 1995; 11:147150.

211. Bogduk N, Christophidis N, Cherry D et al. Epidural Use of Steroids in the Management of Back Pain. Report of Working Party on Epidural Use of Steroids in the Management of Back Pain. National Health and Medical Research Council, Canberra, Commonwealth of Australia, 1994, pp 1-76.

212. Manchikanti L, Pakanati RR, Pampati V. Comparison of three routes of epidural steroid injections in low back pain. Pain Digest 1999; 9:277-285.

213. Hammer M, Doleys D, Chung O. Transforaminal ventral epidural adhesiolysis. Pain Physician 2001; 4:273279

214. Andrade S, Eckman E. Distribution of radiographic contrast media in the epidural space of normal volunteers using a midline transligamentum flavum vs a selective epidural nerve canal injection technique. ISIS Newsletter October, 1992; 6-8.

215. Riew KD, Yin Y, Gilula L et al. Can nerve root injec- tion obviate the need for operative treatment of lumbar radicular pain? A prospective, randomized, controlled, double/blind study. Proceedings of North American Spine Society $16^{\text {th }}$ Annual Meeting. Chicago, 1999, pp 94-95.

216. Shah R, Vad V, Lutz G et al. Transforaminal epidural injections in lumbar radiculopathy: Prospective randomized trial. Proceedings of the North American Spine Society, $15^{\text {th }}$ Annual Meeting New Orleans, 2000, pp 44-45.

217. Krämer J, Ludwig J, Bickert U et al. Lumbar epidural perineural injection: A new technique. Eur Spine J 1997; 6:357-361.

218. Slipman CW. Diagnostic nerve root blocks. In Gonzalez EG, Materson RS (eds). The Nonsurgical Management of Acute Low Back Pain. Demos vermande, New York 1997: pp 115-122.

219. Concato J, Shah N, Horwitz RI. Randomized, controlled trials, observational studies, and the hierarchy of research designs. N Engl J Med 2000; 342:18871892.

220. Goossens MEJB, Evers SMAA, Vlaeyen JWS et al. Principles of economic evaluation for interventions of chronic musculoskeletal pain. Eur J Pain 1999; 3:343353.

221. Ferraz MB, Maetzel A, Bombardier C. A summary of economic evaluations published in the field of rheumatology and related disciplines. Arthritis Rheum 1997; 40:1587-1593.

222. Goossens MEJB, Evers SMAA. Economic evaluation of back pain interventions. J Occup Rehab 1997; 7:1532.

223. Maetzel A, Ferraz MB, Bombardier C. A review of cost effectiveness analyses in rheumatology and related disciplines. Curr Opin Rheumatol 1998; 10:136-140.

224. Ross Davies A, Doyle AT, Lansky D et al. Outcomes assessment in clinical settings: A consensus statement on principles and best practices in project management. Joint Comm Quality Improvement 1994; 20:616.

225. Malter AD, Larson EB, Urban N et al. Cost effectiveness of lumbar discectomy for the treatment of herniated intervertebral disc. Spine 1996; 21:1048-1055.

226. Mueller-Schwefe G, Hassenbusch SJ, Reig E. Cost effectiveness of intrathecal therapy for pain. Neuromodulation 1999; 2:77-84.

227. Kuntz K, Snider R, Weinstein J et al. Cost effectiveness of fusion with and without instrumentation for patients with degenerative spondylolisthesis and spinal stenosis. Spine 2000; 25: 1132-1139.

228. Guo HR, Tanaka S, Halperin WE et al. Back pain prevalence in US industry and estimates of lost work days. Am J Public Health 1999; 89:1029-1035.

229. Manchikanti L, Pampati V, Bakhit CE et al. Effectiveness of lumbar facet joint nerve blocks in chronic low back pain: A randomized clinical trial. Pain Physician 2001; 4: 101-117. 
230. Hopwood M. Outcomes assessment in pain management. In Abram SE (ed). Pain Management. ChurchillLivingstone, Philadelphia, 1998, pp14.1-14.11.

231. Cicala RS, Wright H. Outpatient treatment of patients with chronic pain. Analysis of cost savings. Clin J Pain 1989; 5: 223-226.

232. Lave JR, Frank RG, Schulberg HC et al. Cost effectiveness of treatments for major depression in primary care practice. Arch Gen Psychiatry 1998; 55:645-651.

233. Chang RW, Pellissier JM, Hazen GB. A cost effectiveness analysis of total hip arthroplasty for osteoarthritis of the hip. JAMA 1996; 275:858-865.

234. Wong JB, Sonnenberg FA, Salem DN et al. Myocardial revascularization for chronic stable angina: Analysis of the role of percutaneous transluminal coronary angioplasty based on data available in 1989. Ann Intern Med 1990; 113:852-871.

235. Katz DA, Cronenwett JL. The cost effectiveness of early surgery versus watchful waiting in the management of small abdominal aortic aneurysms. J Vasc Surg 1994; 19:980-991.

236. Tabandeh H. Intraocular hemorrhages associated with endoscopic spinal surgery. Am J Ophthalmol 2000; 129:688-690.

237. Kushner FH, Olson JC. Retinal hemorrhage as a consequence of epidural steroid injection. Arch Ophthalmol 1995; 113:309-313.

238. Ling C, Atkinson PL, Munton CG. Bilateral retinal hemorrhages following epidural injection. $\mathrm{Br} J$ Ophthalmol 1993; 77:316-317.

239. Purdy EP, Ajimal GS. Vision loss after lumbar epidural steroid injection. Anesth Analg 1998; 86:119-122.

240. Victory RA, Hassett P, Morrison G. Transient blindness following epidural analgesia. Anesthesia 1991; 46:940-941.

241. Clark CJ, Whitwell J. Intraocular hemorrhage after epidural injection. Brit Med J 1961; 2:1612-1613.

242. Usubiaga JE, Wikinski JA, Usubiaga LE. Epidural pressure and its relation to spread of anesthetic solution in epidural space. Anesth Analg 1967; 46:440446.

243. Morris DA, Henkind P. Relationship of intracranial, optic-nerve sheath, and retinal hemorrhage. Am J Ophthalmol 1967; 64:853-859.

244. Sampath P, Rigamonti D. Spinal epidural abscess: A review of epidemiology, diagnosis, and treatment. $J$ Spinal Disord 1999; 12:89-93.

245. Wang LP, Haverberg J, Schmidt JF. Incidence of spinal epidural abscess after epidural analgesia. Anesthesiology 1999; 91:1928-1936.

246. Rathmell JP, Garahan MB, Alsofrom GF. Epidural abscess following epidural analgesia. Reg. Anesth Pain Med 2000;25:79-82.

247. Martin RJ, Yuan HA. Neurosurgical care of spinal epidural, subdural, and intramedullary ancesses and arachnoiditis. Orthop Clin North Am 1996; 27:125-
136.

248. Kuker W, Mull M, Mayfrank L, et al. Epidural spinal infection: Variability of clinical and magnetic resonance imaging findings. Spine 1997; 22:544-551.

249. Baker AS, Ojemann RG, Swartz MN et al. Spinal epidural abscess. N Engl J Med 1975; 293:463-468.

250. Knight JW, Cordingley JJ, Palazzo MGA. Epidural abscess following epidural steroid and local anaesthetic injection. Anaesthesia 1997; 52:576-585.

251. Sharif HS. Role of imaging in the management of spinal infections. AJR 1992; 158:1333-1345.

252. DuPen SL, Peterson DG, Williams A et al. Infection during chronic epidural catheterization: Diagnosis and treatment. Anesthesiology 1990; 73:905-909.

253. Donovan Post MJ, Sze G, Quencer RM et al. Gadolinium-enhanced MR in spinal infection. J Computer Assist Tomogr 1990; 14:721-729.

254. Brookman CA, Rutledge MLC. Epidural abscess: Case report and literature review. Reg Anesth Pain Med 2000; 25:428-431.

255. Hlavin ML, Kaminski HJ, Ross JS et al. Spinal epidural abscess: A ten year perspective. Neurosurgery 1990; 27:177-184.

256. Darouiche RO, Hamill RJ, Greenberg SB et al. Bacterial spinal epidural abscess. Review of 43 cases and literature survey. Medicine 1992; 71:369-385.

257. Mackenzie AR, Laing RBS, Smith CC et al. Spinal epidural abscess: The importance of early diagnosis and treatment. J Neurol Neurosurg Psychiatry 1998; 65:209-212.

258. Nussbaum ES, Rigamonti D, Standiford H et al. Spinal epidural abscess: A report of 40 cases and review. Surg Neurol 1992; 38:225-231.

259. Sarubbi FA, Vasquez JE. Spinal epidural abscess associated with the use of temporary epidural catheters: Report of two cases and review. Clin Infec Dis 1997; 25:1155-1158.

260. Yuste M, Canet J, Garcia M et al. An epidural abscess due to resistant Staphylococcus aureus following epidural catheterization. Anaesthesia 1997; 52:150168.

261. Mamourian AC, Dickman CA, Drayer BP et al. Spinal epidural abscess: Three cases following spinal epidural injection demonstrated with magnetic resonance imaging. Anesthesiology 1993; 78:204.

262. Strong, WE. Epidural abscess associated with epidural catheterization: A rare event? Report of two cases with markedly delayed presentation. Anesthesiology 1991; 74:943.

263. Bromage PR. Spinal extradural abscess: Pursuit of vigilance. Br J Anaesth 1993; 70:471-473.

264. Yap KB, Finaly IG. Epidural infection associated with epidural catheterization in a cancer patient with back pain: Case report. Palliat Med 1994; 8:251-253.

265. Kaul S, Meena AK, Sundaram C et al. Spinal extradural abscess following local steroid injection. Neurol 
India 2000; 48:181-183.

266. Chan ST, Leung S. Spinal epidural abscess following steroid injection for sciatica: Case report. Spine 1989; 14:106-108.

267. Goucke CR, Graziotti P. Extradural abscess following local anaesthetic and steroid injection for chronic low back pain. Brit J Anesth 1990; 65:427-429.

268. Scott DB, Hibbard BM. Serious non-fatal complications associated with extradural block in obstetric practice. Br J Anaesth 1990; 64:537-541.

269. Burstal R, Wegener F, Hayes C et al. Epidural analgesia: Prospective audit of 1062 patients. Anaesth Intensive Care 1998; 26:165-172.

270. DeLeon-Casasola OA, Parker B, Lema M et al. Postoperative epidural bupivacaine-morphine therapy: Experience with 4227 surgical cancer patients. Anesthesiology 1994; 81:368-375.

271. Lund PC. Peridural anaesthesia-Rreview of 10,000 cases. Acta Anaesthesiol Scand 1962; 6:143-159.

272. Bryers K, Axelrod P, Michael S et al. Infections complicating tunnelled intraspinal catheter systems used to treat chronic pain. Clin Infect Dis 1995; 21:403408.

273. Holt HM, Anderses SS, Andersen O et al. Infections following epidural catheterisation. J Hosp Infect 1995; 30:253-260.

274. Hunt JR, Rigor BM, Collins JR. The potential for contamination of continuous epidural catheters. Anesth Analg 1977; 56:222-225.

275. Pegues DA, Carr DB, Hopkins CC. Infectious complications associated with temporary epidural catheters. Clin Infect Dis 1994; 19:970-972.

276. Darchy B, Forceville X, Bavoux E et al. Clinical and bacteriologic survey of epidural analgesia in patients in the intensive care unit. Anesthesiology 1996; 85:988998.

277. Jakobsen KB, Christensen M-K, Carlsson PS. Extradural anaesthesia for repeated surgical treatment in the presence of infection. Br J Anaesth 1995; 75:536-540.

278. Carson D, Wildsmith JAW. The risk of extradural abscess [editorial]. Br J Anaesth 1995; 75:520-521.

279. Maslen DR, Jones SR, Crislip MA et al. Spinal epidural abscess. Optimising patient care. Arch Intern Med 1993; 153:1713-1721.

280. Tacconi L, Johnston FG, Symon L. Spinal epidural abscess-review of 10 cases. Acta Neurochir 1996; 138:520-523.

281. Del Curling O, Gower DJ, McWhorter JM. Changing concepts in spinal epidural abscess: A report of 29 cases. Neurosurgery 1990; 27:185-192.

282. Heusner AP. Nontuberculous spinal epidural infections. N Engl J Med 1948; 239:845-854.

283. Hancock DO. A study of 49 patients with acute spinal extradural abscess. Paraplegia 1973; 10:285-288.

284. Danner RL, Hartman BJ. Update of spinal epidural abscess: 35 cases and review of the literature. Rev
Infect Dis 1987; 9:265-274.

285. Bromage PR. Complications and contraindications. In Bromage PR (ed). Epidural Analgesia. WB Saunders, Philadelphia, 1978, pp 469-471.

286. Bromage PR, Benumof JL. Paraplegia following intracord injection during attempted epidural anesthesia under general anesthesia. Reg Anesth Pain Med 1998; 23:104-107.

287. Horlocker TT, Wedel DJ. Neurologic complications of spinal and epidural anesthesia. Reg Anesth Pain Med 2000; 25:83-98.

288. Sandhu H, Morley-Fost P, Spadafora S. Epidural hematoma following epidural analgesia in a patient receiving unfractionated heparin for thromboprophylaxis. Reg Anesth Pain Med 2000; 25:72-75.

289. Osmani O, Afeiche N, Lakkis S. Paraplegia after epidural anesthesia in a patient with peripheral vascular disease: Case report and review of the literature with a description of an original technique for hematoma evacuation. J Spinal Disord 2000; 13:85-87.

290. Tamburrelli F, Leone A, Pitta L. A rare cause of lumbar radiculopathy: Spinal gas collection. J Spinal Disord 2000; 13:451-454.

291. Katz JA, Lukin R, Bridenbaugh PO et al. Subdural intracranial air: An unusual cause of headache after epidural steroid injection. Anesthesiology 1991; 74:615.

292. Mateo E, Lopez-Alarcon MD, Moliner S et al. Epidural and subarachnoid pneumocephalus after epidural technique. Eur J Anesethsiol 1999; 16:413-17.

293. Demierre B, Ramadan A, Hauser H et al. Radicular compression due to lumbar intraspinal gas pseudocyst: case report. Neurosurgery 1988; 22:731-733.

294. Gebarski SS, Gebarski KS, Gabrielson TO et al. Gas as a mass: A symptomatic spinal canalicular collection. J Computer Assist Tomogr 1984; 8:145-146.

295. Kumbar R, West CGH, Gillespie JE. Gas in a spinal extradural cyst. J Neurosurg 1989; 70:486-488.

296. Ricca GF, Robertson JT, Hines RS. Nerve root compression by herniated intradiscal gas. J Neurosurg 1990; 72:282-284.

297. Yoshida H, Shinomiya K, Nakai O et al. Lumbar nerve root compression caused by lumbar intraspinal gas. Spine 1997; 22:348-351.

298. Kane RE. Neurologic deficits following epidural or spinal anesthesia. Anesth Analg 1981; 60:150-161.

299. Rigler ML, Drasner K, Krejcie TC et al. Cauda equina syndrome after continuous spinal anesthesia. Anesth Analg 1991; 72:275-281.

300. Lisai P, Doria C, Crissantu L et al. Cauda equina syndrome secondary to idiopathic spinal epidural lipomatosis. Spine 2001; 26:307-309.

301. Olmarker K, Byrod G, Cornefijord M et al. Effects of methylprednisolone on nucleus pulposus-induced nerve root injury. Spine 1994; 19:1803-1808.

302. Hayashi N, Weinstein JN, Meller ST et al. The effect of epidural injection of betamethasone or bupivacaine 
in a rat model of lumbar radiculopathy. Spine 1998; 23:877-885.

303. Minamide A, Tamaki T, Hashizume H et al. Effects of steroids and lipopolysaccharide on spontaneous resorption of herniated intervertebral discs. An experience study in the rabbit. Spine 1998; 23:870876.

304. Kingery WS, Castellote JM, Maze M. Methylprednisolone prevents the development of autotomy and neuropathic edema in rats, but has no effect on nociceptive thresholds. Pain 1999; 80:555-566.

305. Johansson A, Bennett GJ. Effect of local methylprednisolone on pain in a nerve injury model. A pilot study. Reg Anesth 1997; 22:59-65.

306. Kepes ER, Duncalf D. Treatment of backache with spinal injections of local anesthetics, spinal and systemic steroids. A review. Pain 1985; 22:33-47.

307. Tanner JA. Epidural injections. A new survey of complications and analysis of the literature. J Orthop Med 1996; 18:78-82.

308. Delaney TJ, Rowlingson JC, Carron H et al. Epidural steroid effects on nerves and meninges. Anesth Analg 1980; 58:610-614.

309. Cicala RS, Turner R, Moran E et al. Methylprednisolone acetate does not cause inflammatory changes in the epidural space. Anesthesiology 1990; 72:556-558.

310. MacKinnon SE, Hudson AR, Gentilli R et al. Peripheral nerve injection injury with steroid agents. Plast Reconstr Surg 1982; 69:482-489.

311. Chino N, Awad EA, Kottke FJ. Pathology of propylene glycol administered by perineural and intramuscular injection in rats. Arch Phys Med Rehab 1974; 55:3338 .

312. Benzon HT, Gissen AJ, Strichartz GR et al. The effect of polyethylene glycol on mammalian nerve impulses. Anesth Analg 1987; 66:553-559.
313.

Abram SE, Marsala M, Yaksh TL. Analgesic and neurotoxic effects of intrathecal corticosteroids in rats. Anesthesiology 1994; 81:1198-1205.

314. Latham JM, Fraser RD, Moore RJ et al. The pathologic effects of intrathecal betamethasone. Spine 1997; 22:1558-1562.

315. Slucky AV, Sacks MS, Pallares VS et al. Effects of epidural steroids on lumbar dura material properties. $J$ Spinal Disord 1999; 12:331-340.

316. Manchikanti L. The value and safety of steroids in neural blockade. Part I. AJPM 2000; 10:69-78.

317. Manchikanti L. The value and safety of steroids in neural blockade. Part II. American Journal of Pain Management 2000; 10:122-134.

318. Knight CL, Burnell JC. Systemic side-effects of extradural steroids. Anesthesia 1980; 35: 593-594.

319. Edmonds JC, Vance ML, Hughes JM. Morbidity from paraspinal depo corticosteroid injections for analgesia. Cushing's syndrome and adrenal suppression. Anesth Analg 1991; 72:820-822.

320. Manchikanti L, Pampati V, Beyer C et al. The effect of neuraxial steroids on weight and bone mass density: A prospective evaluation. Pain Physician 2000; 3:357366.

321. Bogduk N.. Nerves of the lumbar spine. In Clinical Anatomy of the Lumbar Spine and Sacrum. Churchill Livingstone, New York, 1997, pp127-143.

322. Parkin IG, Harrison GR. The topographical anatomy of lumbar epidural space. J Anat 1985; 141:211-217.

323. Wiltse LL, Fonesca AS, Amster J et al. Relationship of the dura, Hoffman's ligaments, Batson's plexus, and a fibrovascular membrane lying on the posterior surface of the vertebral bodies and attaching to the deep layer of the posterior longitudinal ligament: An anatomical, radiologic, and clinical study. Spine 1993; 18:1030-1043. 